\title{
Study on Compounds Analysis and Anti Colorectal Cancer Efficacy of Quercus Infectoria Galls' Different Polar Solvent Extracts
}

\section{Aliya Elham}

College of pharmacy, Xinjiang Medical University, Urumqi.

\section{Abdulaziz Arkin}

College of pharmacy, Xinjiang Medical University, Urumqi.

\section{Gulina Kalimanjan}

College of pharmacy, Xinjiang Medical University, Urumqi.

\section{Arfidin Anwar}

College of pharmacy, Xinjiang Medical University, Urumqi.

\section{Wenjie Luo}

College of pharmacy, Xinjiang Medical University, Urumqi.

Mubarak Iminjan ( $D$ 896612093@qq.com )

College of pharmacy, Xinjiang Medical University, Urumqi.

\section{Research Article}

Keywords: Quercus Infectoria Galls, extract, colorectal cancer, entropy weight

Posted Date: July 13th, 2021

DOI: https://doi.org/10.21203/rs.3.rs-659262/v1

License: (c) (i) This work is licensed under a Creative Commons Attribution 4.0 International License. Read Full License 


\title{
Study on compounds analysis and anti colorectal cancer efficacy of Quercus Infectoria galls' different
}

\section{polar solvent extracts}

\author{
Aliya Elham ${ }^{1}$, Abdulaziz Arkin ${ }^{1}$, Gulina Kalimanjan ${ }^{1}$, Arfidin Anwar $^{1}$, Wenjie Luo $^{1}$, Mubarak Iminjan ${ }^{*}$
}

${ }^{1}$ Department of Pharmaceutics and physical chemistry, College of pharmacy, Xinjiang Medical University, Urumqi 830011, China;

\begin{abstract}
Background: Quercus Infectoria galls (QIG) has multiple therapeutic properties and are widely used in Traditional Medicine (TM) as an anti-inflammatory agent for inflammatory bowel disease (IBD). QIG aqueous extract has been verified to inhibit the proliferation of Colorectal cancer (CRC) cells but there is no relevant research on the contribution of material basis of QIG towards the efficacy at present. This research aims to clarify the pharmacodynamic discrepancy of different polar solvent extracts of QIG and the underlying link between material basis and anti CRC efficacy.
\end{abstract}

\footnotetext{
${ }^{*}$ Correspondence to: Dept. of Pharmaceutics and physical chemistry, College of pharmacy, Xinjiang Medical University, Urumqi 830011, China.

E-mail address: 896612093@qq.com (Mubarak Iminjan)
} 
Methods: Four different QIG extracts and residues was prepared by using a modified method and the effective compounds polyphenols, tannins and gallic acid (GA) was determined by analytical methods including Thin Layer Chromatography, Ultraviolet-visible spectrophotometry, High Performance Liquid Chromatography and Infrared spectroscopy. Then GA and four different QIG extracts' anti CRC activity against human HCT-116 and Caco-2 cells were tested in vitro by CCK-8 assay, wound-healing assay and apoptosis assay, at the end entropy weight method was used to comprehensively assess the anti CRC activities for discern the most active one among the four different QIG extracts.

Results: The content determination experiment shows that the content of active compounds in the four extracts increased with the increase of the polarity of the extraction solvent. The content of polyphenols, tannins and GA in aqueous extracts ranks first, reaching $562.66 \pm 8.45 \mathrm{mg} \cdot \mathrm{mL}^{-1}$, $463.85 \pm 4.62 \mathrm{mg} \cdot \mathrm{mL}^{-1}, 169.86 \pm 3.24 \mathrm{mg} \cdot \mathrm{mL}^{-1}$, respectively, followed by methanol, ethanol, and acetone, and the content order of them in residues is opposite to that in extracts. The in vitro pharmacodynamic experiments showed that all four extracts and GA could inhibit the proliferation and migration, induce apoptosis of CRC cells in different degrees. The entropy score of ethanol extract ranks first $(0.5546$ and $0.5436)$, followed by methanol (0.2264 and 0.1989$)$, acetone ( 0.1961 and 0.1011$)$ and aqueous $(0.0596$ and 0.1454$)$. After the intervention of ethanol extract, the proliferation inhibition rate of ethanol extract on HCT-116 and Caco-2 cells reached 76.55\% and 78.8\%, migration inhibition rate reached $76.48 \%$ and $64.85 \%$, and the induced apoptosis rate increased by $20.1 \%$ and $12.6 \%$, respectively. Therefore, it is verified that QIG ethanol extract possess the strongest inhibitory effect on CRC cells. In addition, GA also showed strong anti-cancer activity as the main compound of QIG.

Conclusions: These findings will lead to further studies on the bioactivity-guided isolation of compounds from the ethanol extracts of QIG, and provide a basis for the research of mechanism.

Keywords: Quercus Infectoria Galls, extract, colorectal cancer, entropy weight 


\section{Introduction}

Colorectal cancer (CRC) is one of the most common malignant tumors of the digestive system with high incidence rate and high mortality rate worldwide ${ }^{[1]}$. According to global cancer statistics, the incidence rate of CRC ranks third in the world in 2020 , with about 1148515 people diagnosed with CRC every year ${ }^{[2]}$. Surgical resection, adjuvant chemotherapy and targeted therapy are the main means of clinical treatment of colon cancer, but the recurrence rate and metastasis rate are high in the treatment process, and the overall prognosis is not ideal ${ }^{[3]}$. In addition, the pathogenesis of CRC has always been a key issue in the field of cancer research, and the inflammation and cancer transformation as a potential cause of cancer has attracted more and more attention of researchers ${ }^{[4][5]}$. In recent years, Traditional Medicine(TM) shows good bioactivity and plays important anti cancer role in anti proliferation, pro-apoptosis, anti metastasis, anti angiogenesis, and regulate autophagy, reverse multidrug resistance, balance immunity and enhance the efficacy of radiotherapy and chemotherapy ${ }^{[6]}$.

Quercus infectoria Olivier (also known as the Gall Oak or Quercus lusitanica; family Fagaceae) grow galls as a result of infections by the Cynips gallae tinctoriae wasp. These plants are mainly found in Greece, Asia Minor, Syria, and Iran. Quercus infectoria galls (QIG; also known as Galla Turcica) is rich in polyphenols, and possess antioxidant, damage repair, anti-inflammatory and antibacterial effects in $\mathrm{TM}^{[7]}$. QIG alleviates inflammatory injury by reducing the secretion of inflammatory factors, and enhances the antioxidant activity of colon tissue by scavenging free radicals ${ }^{[8]}$. Traditional Uygur Medicine Xipayi Guyinye ${ }^{[9]}$ is mainly composed of QIG, and this drug has been reported to improve the imbalance between pro-inflammatory factors and anti-inflammatory factors, restore colonic epithelial cells and repair the injured site $^{[10]}$. Previous studies have confirmed that patients with inflammatory bowel disease (IBD) have a significantly increased risk of CRC ${ }^{[11][12]}$. Oral non steroidal anti-inflammatory drugs can reduce the incidence of intestinal tumor and the risk of canceration of IBD, which verifies the certain existence of the mechanism of inflammatory cancer transformation ${ }^{[13][14]}$. As an effective drug for the treatment of IBD ${ }^{[8][15]}$, QIG is considered to be a potential natural drug of $\mathrm{CRC}$, and its aqueous extract has been verified to inhibit the proliferation of CRC cell in vitro ${ }^{[16,17]}$, However. there is no relevant research on the contribution of material basis toward the anti CRC efficacy at present. This research aims to clarify the pharmacodynamic discrepancy of different polar solvent extracts of QIG and the underlying link between material basis and anti CRC efficacy.

In this work, four different QIG extracts and residues prepared by using a modified method reported in literatures and the material basis 
study of them was made by analytical methods including thin layer chromatography (TLC), ultraviolet spectrophotometry (UV), high performance liquid chromatography (HPLC) and Infrared spectroscopy (IR), Then the in vitro anti CRC activity of QIG extracts and GA against human HCT-116 and Caco-2 cells were tested in CCK-8 assay, wound-healing assay and apoptosis assay, then entropy weight method was used to asses the anti CRC activities of the extracts. In the in vitro experiment, 5-FU acted as a positive control drug, and pharmacodynamic study of GA was carried out simultaneously. Finally, this study aims to help finding the relationship between the content of active components and anti cancer effect. We hope our results can provide experimental basis for further in vivo experiments and the application of QIG in CRC therapy as a complement and alternative medicine.

\section{Material and Methods}

\section{Plant material}

QIG were purchased from Baicaotang Medicine Co., Ltd.(Urumqi, China), and identified based on their physical appearances ${ }^{[18]}$ and authenticated at Dept. of Natural medicinal chemistry, College of Pharmacy, Xinjiang Medical University( Urumqi, 830011, China).

\section{Microscopic identification of QIG powders}

QIG were washed, dried and pulverised, and the powders were permeabilized with chloral hydrate to make powder tablets, and then observed under microscope.

\section{Extraction of the plant material}

Acetone, methanol, ethanol and aqueous extractions were prepared using a modified method reported in literatures ${ }^{[19,20]}$. QIG were washed, dried and pulverised before dissolved, and heating reflux in respective solvents at a ratio of $100 \mathrm{~g}$ of dried crude powder per $800 \mathrm{~mL}$ of absolute 
solvent for 3 times, $0.5 \mathrm{~h}$ each time. The extracts were filtered using Whatman filter papers, then put the dregs in the dark and dry them at room temperature. The acetone, methanol, ethanol and aqueous filtrates were concentrated using a rotary evaporator at $55{ }^{\circ} \mathrm{C}$. The resulting pellets were pounded to dryness at $50{ }^{\circ} \mathrm{C}$ for two days to produce powdery and brown crude extracts. The crude extracts and residue were weighed and stored in sealed vials at $4{ }^{\circ} \mathrm{C}$ for further use.

\section{Determination of polyphenols and tannins by UV-Vis.}

Determinations of phenolic and tannin compounds in QIG extracts were made by UV-Vis (Shimadzu, JP) means $(\lambda=760 \mathrm{~nm})$ following the method recorded in Chinese Pharmacopoeia (2020 Edition). The results of the polyphenols and tannins content were expressed in GA equivalents(Solarbio, Beijing, China). The results were calculated from the equation of the calibration curve prepared for GA standard solution in the concentration range $2.56-15.36 \mu \mathrm{g} \cdot \mathrm{mL}^{-1}(2.56,5.12,7.68,10.24,12.8,15.36)$. The content of tannins is equal to the content of total polyphenols minus the content of the polyphenols which is not adsorbed by casein. Each sample was diluted appropriately to the range of the standard curve. All analyses were performed in triplicate.

\section{TLC Identification of GA}

After preparing $1 \mathrm{mg} \cdot \mathrm{mL}^{-1} \mathrm{GA}$ standard solution, $5 \mathrm{mg} \cdot \mathrm{mL}^{-1}$ extracts and residues sample solution, the samples was spotted on polyamide thin-layer plate, put into the mobile phase (methanol: chloroform $=2: 1$ ) to develop, took out and dried in the dark, then developed color with $2 \%$ ferric chloride ethanol solution, Observe whether the extracts and residues of each group contain the same rate of flow (RF value) as GA standard solution.

\section{HPLC detemination of GA}




\section{(a) Instrumentation}

Determinations of GA in QIG extracts were made by HPLC (Agilent, USA) means following the modified method recorded in Chinese Pharmacopoeia(2020 Edition). HPLC system used for the optimized method consisting of a column oven, a quaternary pump, an automatic injector, and a diode array detector. system wascontrolled by Chromeleon 7.2 software (all from Agilent).

\section{(b) Chromatographic conditions.}

A Waters $\mathrm{C}_{18}$ column $(250 \mathrm{~mm} \times 4.6 \mathrm{~mm}, 5 \mu \mathrm{m}$ particle size $)$ was used as the stationary phase. The mobile phase consisted of $0.05 \%$ phosphoric acid methanol $(93: 7 \mathrm{v} / \mathrm{v})$ with isocratic elution was delivered at a flow rate of $1.0 \mathrm{~mL} \cdot \mathrm{min}^{-1}$. mobile phase was prepared daily and filtered with a $0.45 \mu \mathrm{mmembrane}$ filter (Millipore Corp., USA). Column temperature was set at $35^{\circ} \mathrm{C}$. And, samples were analyzed at a wavelength of $271 \mathrm{~nm}$ and injected at $10 \mu \mathrm{L}$ injection volume.

\section{(c) Preparation of stock, working, and standard curve solutions.}

Standard stock solutions $\left(0.1 \mathrm{mg} \cdot \mathrm{mL}^{-1}\right)$ of GA were prepared by dissolving an accurately weighed $6 \mathrm{mg}$ of reference standards in $10 \mathrm{~mL}$ of deionised water in a $10 \mathrm{~mL}$ volumetric flask. Solutions were kept at $20^{\circ} \mathrm{C}$ until use. For the linearity studies, a 5-point calibration curve was prepared by diluting the working standard solution with deionised water and the range of this calibration curve $\left(\right.$ from 10.0 to $\left.160.0 \mu \mathrm{g} \cdot \mathrm{mL}^{-1}\right)$.

\section{(d) Validation of method.}

Method validation of quantitative analysis was performed on parameters such as linearity, precision, recovery, and specificity of GA. linearity of response was performed using plotting peak areas against the concentration of the injected standard. Method precision was evaluated based on 
intraday and interday variability. Intraday variability was conducted by injecting the triplicate determination of quality control samples $\left(400 \mu \mathrm{g} \cdot \mathrm{mL}^{-1}\right)$ six consecutive times in the same day. Interday variability was realized by using the same quality control samples for six successive days. Relative standard deviation (RSD) values were calculated for the integration area and considered to be the measure of precision. Accuracy of the method was determined by addition of known amounts of GA standard drugs ( at level of 50, 100, and 150\% levels) into infusion samples in triplicate. In this work, the mean recovery of the GA concentration was $100 \pm 2 \%$ for acceptance. The specificity of the method was proved by injecting the standard and sample solution. There was no interference with the retention times of analyte peaks. The optimized method was able to separate the possible formulation peaks and diluent peaks from the retention times of the analytes. Both the limits of detection and quantitation (LOD and LOQ) values were calculated by using slope and Y-intercept. according to ICH recommendations ${ }^{\text {[21]. }}$ Relatively low LOQ and LOD values confirm high sensitivity of the introduced HPLC method.

\section{(e) Application to drug product samples}

This validated assay was used to quantify the amount of GA in different QIG extracts and residues. Accurately weigh $0.8 \mathrm{~g}$ of each extract and $4 \mathrm{~g}$ of drug residue, put them into $25 \mathrm{~mL}$ brown flask respectively, add distilled water, dissolve them with ultrasonic wave for 15 min, and constant volume to scale at room temperature. Take $1.0 \mathrm{~mL}$ each solution and place it in $250 \mathrm{~mL}$ brown measuring bottle, add distilled water to set the volume to the scale. The solution was filtered through a $0.45 \mu \mathrm{m}$ membrane filter.

\section{IR Analysis of extracts and residues}

Take $2.0 \mathrm{mg}$ of each sample, add $200 \mathrm{mg}$ of dry potassium bromide powder, grind it evenly with agate research bowl, place it in the mold, make transparent sheet with tablet pressing machine (pressure about $80-100 \mathrm{KN}$ ), and then put $\mathrm{KBr}$ sheet containing sample into sample frame of infrared spectrometer ( IR-Prestige21. Shimadzu, JP) for determination. Both the sample and KBr should be dried and ground to a particle size of less than $2 \mu \mathrm{m}$, to avoid the influence of scattered light. 


\section{Cell lines and treatment}

HCT-116 (CRC human cell line) and Caco-2 (CRC human cell line) were purchased from Procell Life Science\&Technology Co,.Ltd. (Shanghai, China) and the passage number of them in this experiment was between 4 and 5. Cell medium was DMEM (BI, Israel) containing $100 \mathrm{IU} \cdot \mathrm{mL}^{-1}$ penicillin (Beyotime Biotechnology, Shanghai, China) and 10\% fetal bovine serum (BI, Israel). The cell incubator maintained $5 \% \mathrm{CO}_{2}$ and $37^{\circ} \mathrm{C}$.

\section{CCK8 Assay}

CRC cells $\left(5 \times 10^{5} \cdot \mathrm{mL}^{-1}\right)$ were added to a 96 -well plate with $100 \mathrm{ul}$ of cell suspension per well. 5 -fu (Solarbio, Beijing, China) was selected as the positive drug in this experiment. After treating the cells with QIG extracts $\left(0.05-0.5 \mathrm{mg} \cdot \mathrm{mL}^{-1}\right), \mathrm{GA}\left(0.02-0.2 \mathrm{mg} \cdot \mathrm{mL}^{-1}\right), 5-\mathrm{fu} \quad\left(0.005-0.1 \mathrm{mg}^{-} \mathrm{mL}^{-1}\right)$ at different concentrations for different times(12-72h), CCK-8 reagent (Biosharp, Shanghai, China) was added with $10 \mu$ each pore. Then the mixture was incubated in a $37^{\circ} \mathrm{C}$ incubator for $1.5 \mathrm{~h}$, and the absorbance was tested with a microplate reader at $450 \mathrm{~nm}$. Cell inhibition rate calculated using $\operatorname{Eq}(1)$

$$
\text { Cell inhibition }(\%)=\frac{\begin{array}{c}
\text { Absorbance } \\
(\text { test sample - blank })
\end{array}}{\begin{array}{c}
\text { Absorbance } \\
\text { (negative sample - blank) }
\end{array}} \times 100
$$

\section{Wound-healing assay}

When the HCT-116 and Caco-2 cells were cultured into confluent monolayers in a six well cell culture cluster, a $10 \mu 1$ sterile tip was used to draw multiple lines on the cell layer and different concentrations of QIG extract $\left(0.1,0.3,0.5 \mathrm{mg} \cdot \mathrm{mL}^{-1}\right)$, and $\mathrm{GA}\left(0.1,0.15,0.2 \mathrm{mg} \cdot \mathrm{mL}^{-1}\right)$ were 
added to cells. The average level of cell migration was analyzed after obtaining an image at $0 \mathrm{~h}, 24 \mathrm{~h}$ with an $10 \times$ objective lens of an inverted microscope (Nikon, JP).

\section{Apoptosis assay}

Cells were digested with $0.25 \%$ trypsin after treatment with QIG extract $\left(0.3 \mathrm{mg} \cdot \mathrm{mL}^{-1}\right)$ and GA $\left(0.1,0.15,0.2 \mathrm{mg}^{-} \mathrm{mL}^{-1}\right)$ for $24 \mathrm{~h}$, and then collected by centrifugation at $1500 \mathrm{r} \cdot \mathrm{min}^{-1}$. After that, they were washed twice with PBS and dyed with Annexin V-FITC and PI for 20 min under $4{ }^{\circ} \mathrm{C}$ without light. The level of apoptosis was assessed by flow cytometry (Becton-Dickinson, USA).

\section{Statistical analysis}

The statistical significance between groups was performed with SPSS 26.0 using one-way ANOVAs. It was regarded as statistically significant by $P$ values $<0.05$. The data were expressed as mean \pm sd of three independent experiments.

\section{Entropy weight}

Entropy can measure system uncertainty, and entropy weights can represent the relative importance of factors ${ }^{[22]}$. Assuming that $n$ extracts were selected as samples and $m$ evaluation indexes were designed, the dataset related to the extracts would be presented through the matrix $x_{i j}$, where $i$ $=1,2, \ldots, \mathrm{n} ; j=1,2, \ldots, \mathrm{m} ; x_{i j}$ is the value of the $i$ th extract with regard to the parameter $j$; then the data are standardized using Eqs.(2a,2b). $M j$ and $m j$ are the maximum and minimum rate values of index $j$, respectively, in which $\operatorname{Eq}(2 \mathrm{a})$ use for positive index, $\operatorname{Eq}(2 \mathrm{~b}) \mathrm{use}$ for reverse index. Next, The entropy value for index $j$ named $e_{j}$ could be defined using Eqs. (3-4). The weight of each parameter was finally estimated using Eq. (5-6), where $w_{j}$ is the index weight of $j$ th parameter, and $n$ is the number of the evaluation indicator. Finally the index weight $w_{j}$ and $p_{i j}$ are multiplied to get the comprehensive score of each evaluation object using Eq. (7). 


$$
\begin{array}{cc}
\mathrm{r}_{\mathrm{ij}}=\frac{x_{i j}-m_{j}}{M_{j}-m_{j}} & \mathrm{r}_{\mathrm{ij}}=\frac{M_{j}-x_{i j}}{M_{j}-m_{j}} \\
p_{i j}=\frac{\mathrm{r}_{i j}^{\prime}}{\sum_{i=1}^{n} \mathrm{r}_{i j}^{\prime}} & \mathrm{e}_{\mathrm{j}}=-\frac{1}{\ln n} \sum_{i=1}^{n} p_{i j} \ln \left(p_{i j}\right) \\
\mathrm{g}_{j}=1-e_{j} & \mathrm{w}_{j}=\frac{\mathrm{g}_{j}}{\sum_{i=1}^{n} g_{j}} \mathrm{j}=1,2,3 \ldots . . \mathrm{m}
\end{array}
$$

$$
\mathrm{S}=\sum_{j=1}^{m} \mathrm{~W}_{j} \times \mathrm{p}_{i j}
$$

\section{Results}

\section{Microscopic identification of QIG powders}

The microscopic characteristics of QIG powder are shown in Fig. 1. QIG powder is light yellow, the thin-walled cells are oval or irregular, and the pore pattern is obvious; the round or rectangular cell cavity of the stone cells is large, with a diameter of 5-10 $\mu \mathrm{m}$. The brown globules are integrated or single, 5-20 $\mu \mathrm{m}$ in diameter. The starch grains are round or oval, and the umbilical points are fissure or herringbone, with a diameter of 15-30 $\mu \mathrm{m}$. Calcium oxalate clusters with a diameter of 20-35 $\mu \mathrm{m}$ are present; the conduit is multi-threaded. The wall of the non-glandular hairs is thick and slightly lignified ${ }^{[23]}$. 


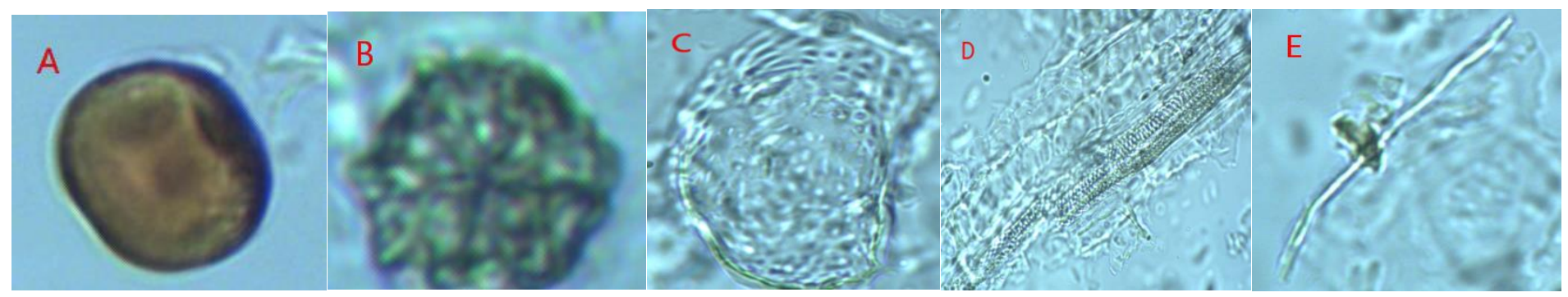

Fig.1 The microcosmic structures of QIG powders $(\times 100)$. A:Brown starch granules; B: Calcium oxalate cluster; C: Parenchyma cell; D: Spiral vessel; E: Nonglandular hair

\section{Extraction yield of the QIG extracts and residues}

The temperature of each solvent is controled at acetone $\left(58^{\circ} \mathrm{C}\right)$, ethanol $\left(80^{\circ} \mathrm{C}\right)$, methanol $\left(65^{\circ} \mathrm{C}\right)$, aqueous $\left(100{ }^{\circ} \mathrm{C}\right)$ according to their own boiling point. The extraction yield (\%) recorded is illustrated in Table 1 based on the nature of the solvents used. The methanol extract produced the highest yield (77.96\% of the dry powder), followed by the ethanol extract (75.48\%), the acetone extract $(70.17 \%)$ and the aqueous extract $(68.86 \%)$.

\section{Polyphenols and tannins' analysis}

According to the standard curve $(y=0.0628 \mathrm{x}+0.0495, \mathrm{R}=0.9999)$ drawn by GA standard solution, the content of polyphenols and tannins in the four extracts and residues were calculated in Table 1.Tannins and polyphenols are water-soluble components, so the content of tannins and polyphenols increases with the increase of solvent polarity. The content of this component in QIG extracts is aqueous $>$ methanol $>$ ethanol $>$ acetone, which is opposite in the residue, and the content in crude drug is basically the same after conversion. 


\section{TLC identification of GA}

The results of TLC are as shown in Fig. 2(A,B). GA is contained in all extracts and residues, and the content of GA in residues is significantly less than that in extracts.

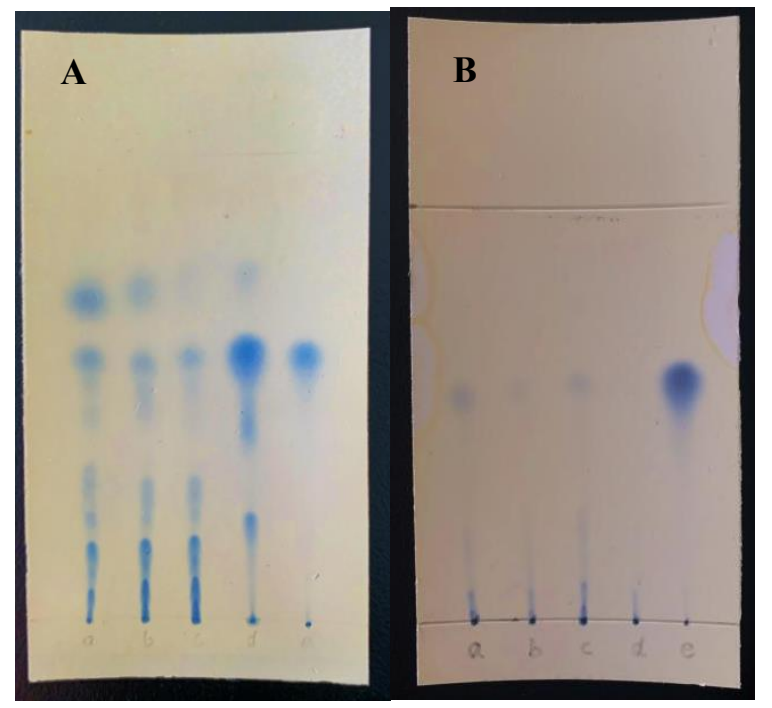

Fig.2 Results of thin layer chromatography of each sample. A:extracts.B: residues. From left to right were methanol, ethanol, acetone, aqueous samples and GA standard solution in both plate.

\section{HPLC determination of GA}

The chromatograms of the standard solution, sample and blank are as Fig. 3. The negative control solution has no interference at the 
corresponding position of the chromatographic peak of the control solution, which is indicated that GA can be determined under this condition. The characteristic parameters for regression equations of the proposed HPLC method are given in Table 2. The values of LOD in the developed method were $0.29 \mu \mathrm{g} \cdot \mathrm{mL}^{-1}$, and LOQ values were $0.91 \mu \mathrm{g} \cdot \mathrm{mL}^{-1}$ with \%RSD less than five (accepted criteria in less than $10 \%$ ). The precision data for both inter- and intraday analysis of GA in the quality control samples at three levels is depicted in Table 2 . The results of precision and accuracy were found to be within the acceptable limits, which indicated that the new method is precise and accurate. The determination results of GA content in each sample are shown in Table 1.

Table 1 The extraction yield (\%) and content of components of the QIG crude extracts and residues prepared with different polar solvents

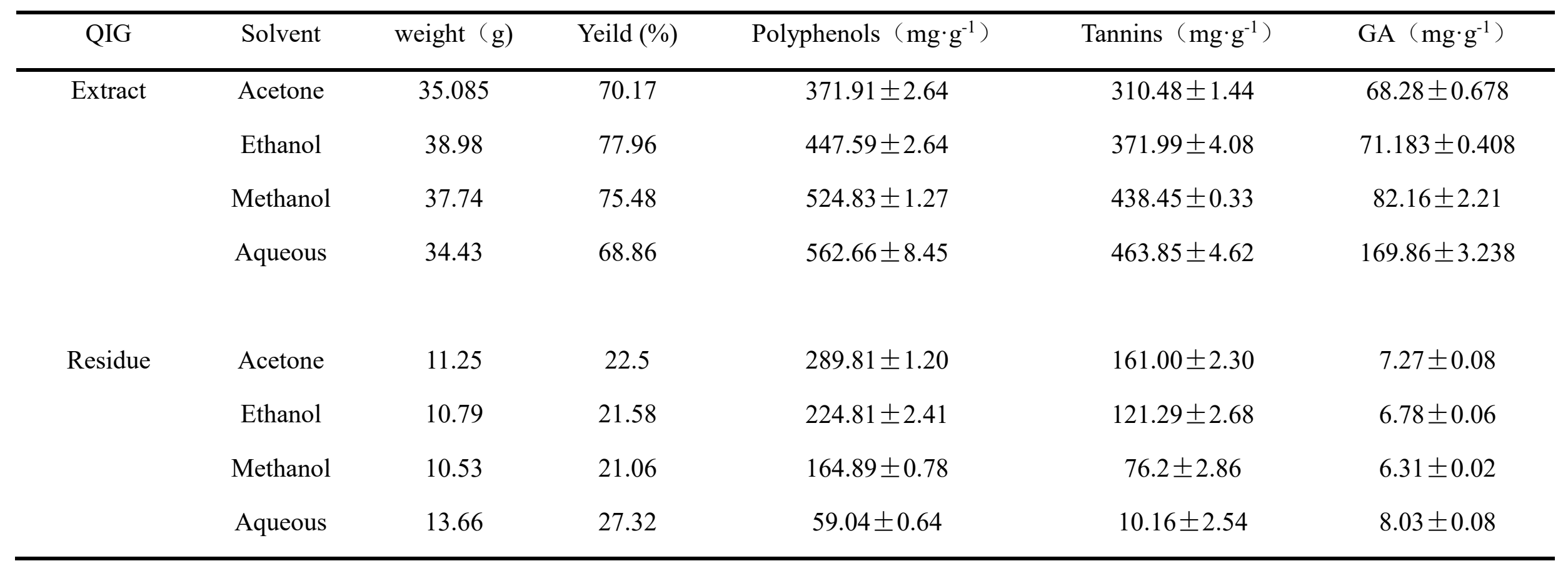




\begin{tabular}{ccccccc}
\hline \multirow{2}{*}{ Crude drug } & Acetone & 50.02 & 92.67 & $661.72 \pm 2.98$ & $471.58 \pm 1.25$ & $75.55 \pm 0.68$ \\
& Ethanol & 50.04 & 99.54 & $672.40 \pm 3.18$ & $493.29 \pm 1.76$ & $77.96 \pm 0.36$ \\
& Methanol & 50.05 & 96.54 & $689.71 \pm 0.53$ & $514.64 \pm 3.16$ & $88.47 \pm 2.24$ \\
& Aqueous & 50.01 & 96.18 & $621.70 \pm 7.98$ & $474.01 \pm 2.16$ & $177.88 \pm 3.18$ \\
\hline
\end{tabular}

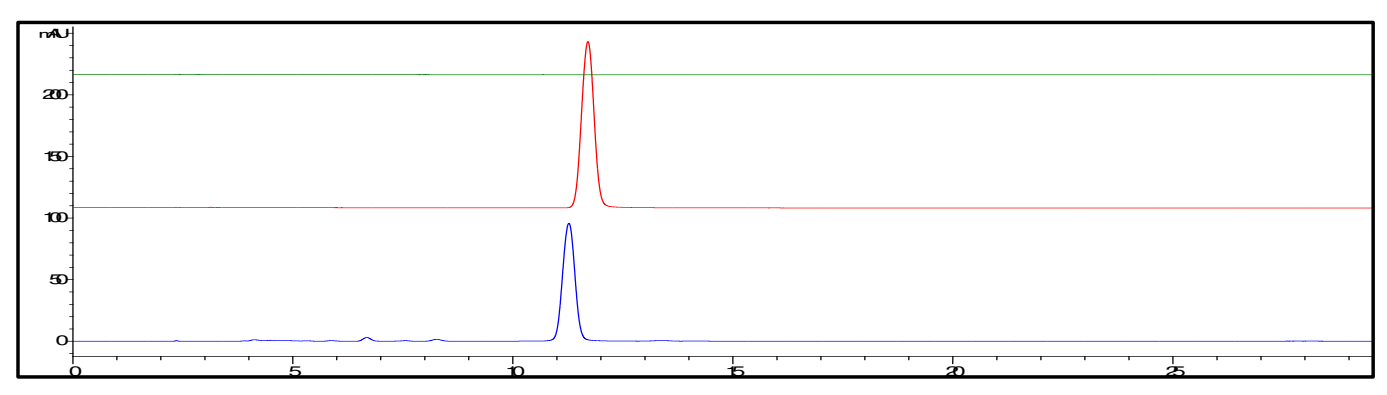

Fig.3 The chromatograms of stander, sample and blank. Note: standard (- $(-$, sample (- $(-)$ and blank $(-)$

Table 2 Analytical parameters for GA

\begin{tabular}{cc}
\hline Analytical parameter & Value \\
\hline Wavelength & $271 \mathrm{~nm}$ \\
\hline
\end{tabular}




\begin{tabular}{|c|c|c|}
\hline Retention time (min) & & 11.717 \\
\hline $\begin{array}{l}\text { Theoretical plate (mean } \pm \\
\text { SD) }\end{array}$ & & $4973.38 \pm 3.58$ \\
\hline Linear range $\left(\mu \mathrm{g} \cdot \mathrm{mL}^{-1}\right)$ & & $10 \sim 160$ \\
\hline Linear equation & & $\begin{aligned} \mathrm{Y}= & 32.802 \mathrm{X}-33 \\
& 9.88\end{aligned}$ \\
\hline Correlation (r) & & 0.9991 \\
\hline $\begin{array}{l}\text { Detection limit } \\
\left(\mu \mathrm{g} \cdot \mathrm{mL}^{-1}\right)\end{array}$ & & 0.29 \\
\hline $\begin{array}{l}\text { Quantification limit } \\
\qquad\left(\mu \mathrm{g} \cdot \mathrm{mL}^{-1}\right)\end{array}$ & & 0.91 \\
\hline \multirow[t]{2}{*}{ Accuracy } & $\begin{array}{l}\text { Recovery } \\
(\%)\end{array}$ & 98.87 \\
\hline & $\operatorname{RSD}(\%)$ & 2.6 \\
\hline \multirow{2}{*}{ Precision RSD (\%) } & Intraday & 1.2 \\
\hline & Interday & 1.8 \\
\hline
\end{tabular}




\section{IR analysis}

The IR spectra of the raw medicinal powder, extracts and residues are shown in Fig.4(A, B, C). The spectrum shown in the figure is very complex and including multiple characteristic absorption peaks. A series of high intensity characteristic absorption was found in $1750-1400 \mathrm{~cm}^{-1}$ region. The peak at $1708 \mathrm{~cm}^{-1}$ is related to the stretching vibration of $\mathrm{C}=\mathrm{O}$ in gallic phthalein group. Because of the stretching vibration of $\mathrm{C}=$ $\mathrm{C}$ group and the deformation and in plane bending of aromatic skeleton and $\mathrm{C}-\mathrm{H}$, characteristic peaks of which appear at $1612 \mathrm{~cm}^{-1} .1535 \mathrm{~cm}^{-1}$ and $1446 \mathrm{~cm}^{-1}, 1309 \mathrm{~cm}^{-1}$ and $1203 \mathrm{~cm}^{-1}$ are related to the in plane bending vibration of $-\mathrm{CH} 2$ and $-\mathrm{CH} 3$. The absorption peak at $1029 \mathrm{~cm}^{-1}$ is attributed to the stretching vibration of $\mathrm{C}-\mathrm{O}$. The peak at $871 \mathrm{~cm}^{-1}$ may be related to the out of plane bending vibration of $\mathrm{C}-\mathrm{O}$. In addition, the absorption peak of $\mathrm{C}-\mathrm{C}$ stretching vibration was appeared at $759 \mathrm{~cm}^{-1}$. Table 3 lists the detailed peak out position of each sample and the expansion change of functional groups at that location. It can be seen that the characteristic peak does not produce obvious displacement or change, nor a new or disappeared diffraction peak, which is because there is no appearance of a new functional group or a certain reaction of the original functional group. With the change of extraction solvent, some characteristic bands show that the absorbance or wave number still slightly change. By comparing the infrared absorption spectra of extracts and residues extracted by different polar solvents, the characteristic absorption band in the wave number range between $3000 \mathrm{~cm}^{-1}$ and $3500 \mathrm{~cm}^{-1}$ changes to low intensity peak, and the peak type becomes wider, which may be caused by the stretching vibration caused by gallic acid, methyl gallate and tannins in the extracts and residues. These changes indicate that the increase of solvent polarity may affect the $-\mathrm{OH}$ bond in the molecule. In addition, the polarity of the extraction solvent does not affect the molecular structure of $\mathrm{C}-\mathrm{H}$ bond. In conclusion, although the extraction solvent has an effect on the proportion of its components, it has no effect on the main molecular structure of the medicinal materials, and will not cause the fundamental change of chemical structure. 

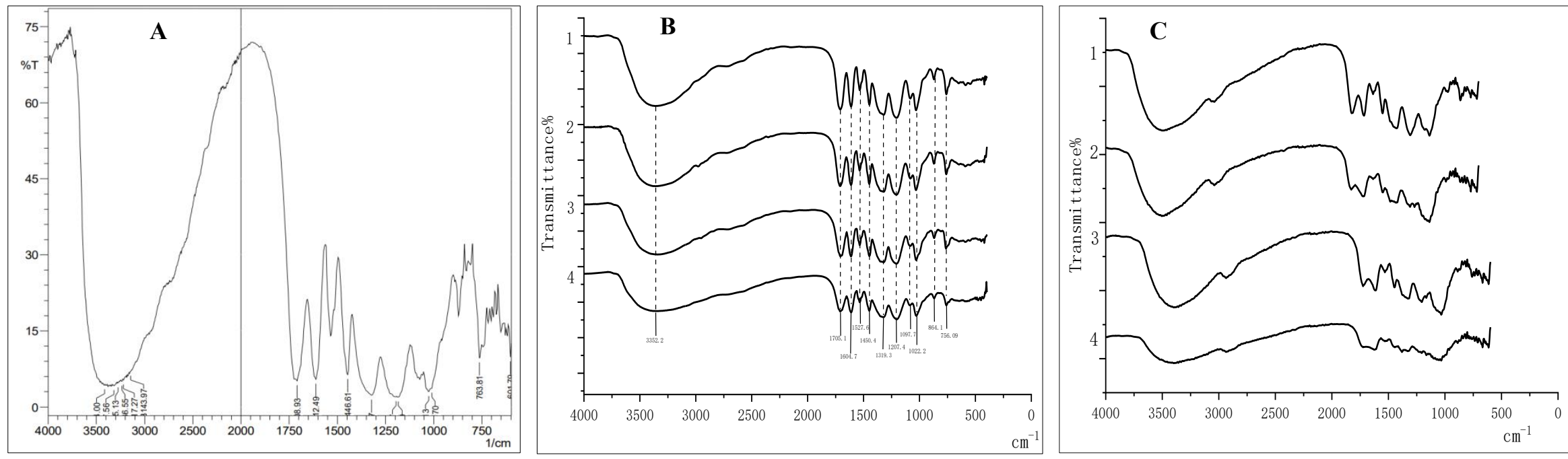

Fig. 4 IR spectra of QIG powder, extracts and residues. A:Infrared spectrogram of QIG powder. B:1 4 are the infrared spectra of QIG acetone, ethanol, methanol and aqueous extract, respectively. C:1 4 are the infrared spectra of QIG acetone, ethanol, methanol and aqueous residue, respectively.

Table 3 Wavenumber assignments of FTIR spectra of QIG powder, extracts and residues.

\begin{tabular}{|c|c|c|c|c|c|c|c|c|c|}
\hline \multirow{2}{*}{$\begin{array}{c}\text { QIG } \\
\text { Powder }\end{array}$} & \multicolumn{4}{|c|}{ QIG extract } & \multicolumn{4}{|c|}{ QIG residue } & \multirow{2}{*}{ Assignment } \\
\hline & Acetone & Ethanol & Methanol & Aqueous & Acetone & Ethanol & Methanol & Aqueous & \\
\hline $3217-3414$ & $3344-3360$ & $3344-3360$ & $3321-3340$ & $3282-3340$ & $3332-3383$ & $3309-3383$ & $3309-3383$ & $3232-3383$ & -OH stretching vibration \\
\hline
\end{tabular}




\begin{tabular}{|c|c|c|c|c|c|c|c|c|c|}
\hline 1708 & 1708 & 1708 & 1708 & 1708 & 1712 & 1724 & 1724 & 1724 & $\mathrm{C}=\mathrm{O}$ stretching vibration \\
\hline 1612 & 1612 & 1612 & 1612 & 1612 & 1612 & 1620 & 1612 & 1620 & \\
\hline 1535 & 1535 & 1535 & 1535 & 1535 & 1531 & 1531 & 1531 & 1523 & $\begin{array}{c}\text { Aromatic } \mathrm{C}=\mathrm{C} \text { groups, aromatic skeleton with } \mathrm{C}-\mathrm{H} \text { in-plane } \\
\text { deforming and stretching }\end{array}$ \\
\hline 1446 & 1446 & 1450 & 1446 & 1450 & 1446 & 1446 & 1446 & 1442 & \\
\hline 1323 & 1309 & 1309 & 1319 & 1319 & 1323 & 1319 & 1327 & 1330 & \\
\hline & & & & & & & & & Symmetric in-plane bending vibration of - $\mathrm{CH} 3$ and $-\mathrm{CH} 2$ \\
\hline 1195 & 1203 & 1207 & 1203 & 1203 & 1203 & 1203 & 1203 & 1203 & \\
\hline 1026 & 1029 & 1029 & 1029 & 1029 & 1033 & 1033 & 1033 & 1033 & $\mathrm{C}-\mathrm{O}$ stretching vibration \\
\hline 871 & 871 & 871 & 867 & 867 & 871 & 887 & 887 & 887 & out-of-plane bend of C-O \\
\hline 763 & 759 & 759 & 763 & 759 & 759 & 759 & 759 & 736 & C-C stretching vibration \\
\hline
\end{tabular}




\section{CCK8 assay}

Table 4 show that QIG extracts and GA have different degrees of inhibition on the proliferation of two kinds of CRC cells after incubation at different concentrations and time. It increases with the increasing of concentration $(P<0.05)$ and the extension of time $(P<0.05)$. According to the data in Table 5, the IC50 values of each test drug on two kinds of CRC cells are different, among them the IC50 values of QIG acetone, ethanol, methanol and aqueous extracts on HCT-116 cells after 12, 24, 48 and 72 hours are range from $0.313 \sim 0.988 \mathrm{mg} \cdot \mathrm{mL}^{-1}, 0.131 \sim 0.53$ $\mathrm{mg} \cdot \mathrm{mL}^{-1}, 0.107 \sim 0.379 \mathrm{mg} \cdot \mathrm{mL}^{-1}$ and $0.1 \sim 0.262 \mathrm{mg} \cdot \mathrm{mL}^{-1}$, respectively; and the IC50 values on Caco-2 cells are range from $0.966 \mathrm{mg} \cdot \mathrm{mL}^{-1}$ $\sim 1.382 \mathrm{mg} \cdot \mathrm{mL}^{-1}, 0.404 \sim 0.522 \mathrm{mg} \cdot \mathrm{mL}^{-1}, 0.246 \sim 0.341 \mathrm{mg} \cdot \mathrm{mL}^{-1}, 0.122 \sim 0.312 \mathrm{mg} \cdot \mathrm{mL}^{-1}$. So the ethanol extract showed the strongest anti CRC activity and others. Additionally, GA also showed strong anticancer activity as one of the important component of QIG. The maximum inhibition rate and IC50 value of GA on HCT-116 and Caco-2 cells were $86.54 \%$ and $0.07 \mathrm{mg} \cdot \mathrm{mL}^{-1}, 80.3 \%$ and $0.083 \mathrm{mg} \cdot \mathrm{mL}^{-1} \mathrm{respectively} \mathrm{after} 72 \mathrm{hours}$ of treatment. The preliminary results can provide a reference for further research in the future, and can also provide ideas for the treatment of colon cancer.

HCT-116 and Caco-2 cell strains were isolated from the colon tissues of white male CRC patients over 70 years old. The growth of normal HCT-116 cells was scattered, the cell morphology was spindle, and the adhesion was relatively weak, as shown in Fig. 5 (A). The normal Caco-2 cells were aggregated and grew, and the cell morphology was clear and round, while the cells were closely connected and adhered firmly, as shown in Fig. 5 (E). The morphological changes of two kinds of colon cancer cells were observed under microscope after incubation with different concentrations of ethanol extract for 48 hours. The experimental groups (ethanol extract concentration $0.1,0.3,0.5 \mathrm{mg} \cdot \mathrm{mL}^{-1}$ ) showed different degrees of damage. With the increase of the concentration of active ingredients, the number of adherent cells decreased significantly. HCT-116 cells gradually increased in shrinkage, abscission and roundness. The cells began to condense into spheres and lost their fixed cell morphology, as shown in Fig. 5 (B, C, D). Caco-2 cells showed different degrees of fragmentation, increased cell fragments, formed irregular clusters, and lost the original regular tight junction, as shown in Fig. 5 (F, G, H). 

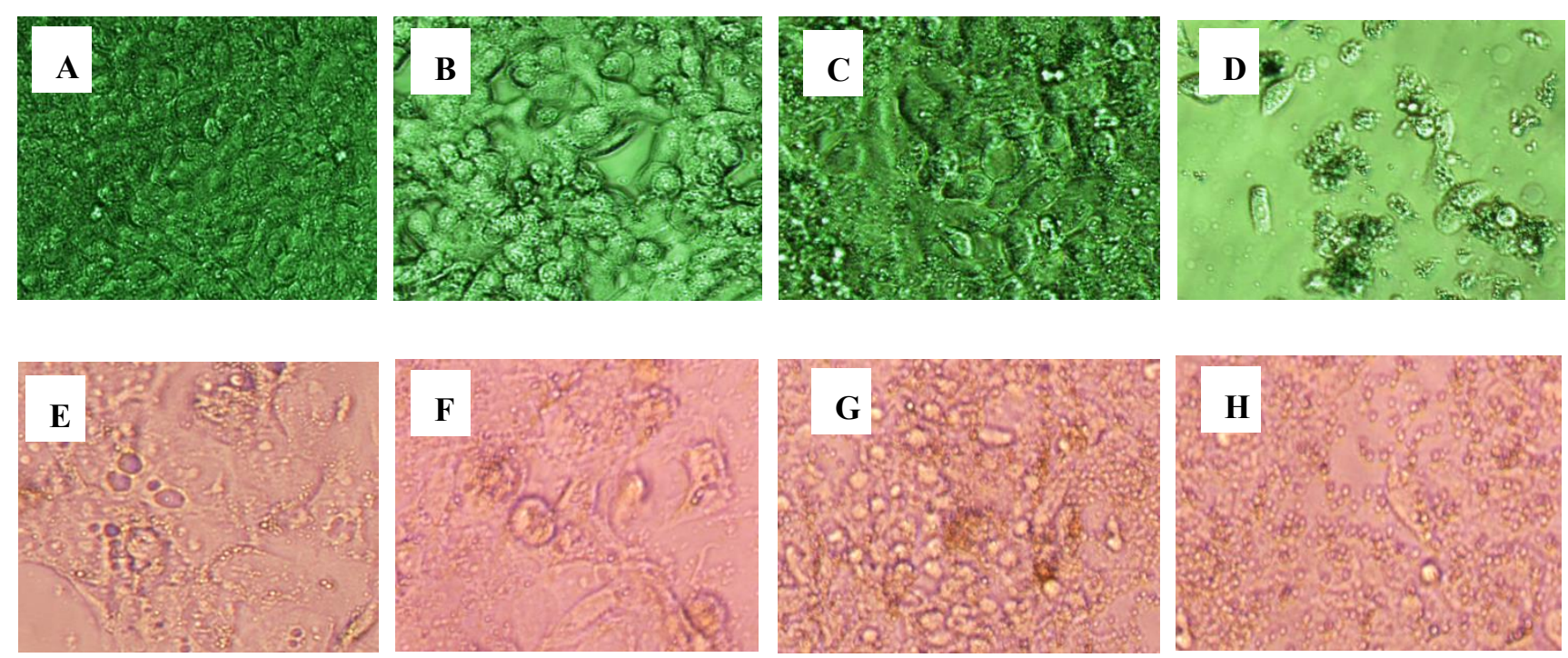

Fig.5 Morphology of two kinds of CRC cells before and after intervention with ethanol extract (X100). A. B, C and D were the morphology of HCT-116 cells at $0,0.1,0.3$ and $0.5 \mathrm{mg} \cdot \mathrm{mL}^{-1}$, respectively; $\mathbf{E}, \mathbf{F}, \mathbf{G}$ and $\mathbf{H}$ were the morphology of Caco-2 cells at $0,0.1,0.3$ and $0.5 \mathrm{mg} \cdot \mathrm{mL}^{-1}$, respectively.

Table 4 QIG extracts on the growth inhibition rate of -2 HCT-116 and Caco-2 cells（\%)

\begin{tabular}{|c|c|c|c|c|c|c|c|c|c|}
\hline \multirow{2}{*}{ Extract } & \multirow{2}{*}{$\begin{array}{c}\mathrm{C} \\
\left(\mathrm{mg} \cdot \mathrm{mL}^{-1}\right)\end{array}$} & \multicolumn{4}{|c|}{ HCT-116 } & \multicolumn{4}{|c|}{ Caco-2 } \\
\hline & & $12 \mathrm{~h}$ & $24 \mathrm{~h}$ & $48 \mathrm{~h}$ & $72 \mathrm{~h}$ & $12 \mathrm{~h}$ & $24 \mathrm{~h}$ & $48 \mathrm{~h}$ & $72 \mathrm{~h}$ \\
\hline $5-\mathrm{fu}$ & 0.1 & $47.14 \pm 1.21^{* *}$ & $60.74 \pm 0.88^{* *}$ & $87.49 \pm 0.89^{* *}$ & $91.55 \pm 1.39^{* *}$ & $30.2 \pm 3.12^{* *}$ & $59.78 \pm 1.27^{* *}$ & $81.46 \pm 0.98^{* *}$ & $84.71 \pm 3.28^{* *}$ \\
\hline
\end{tabular}




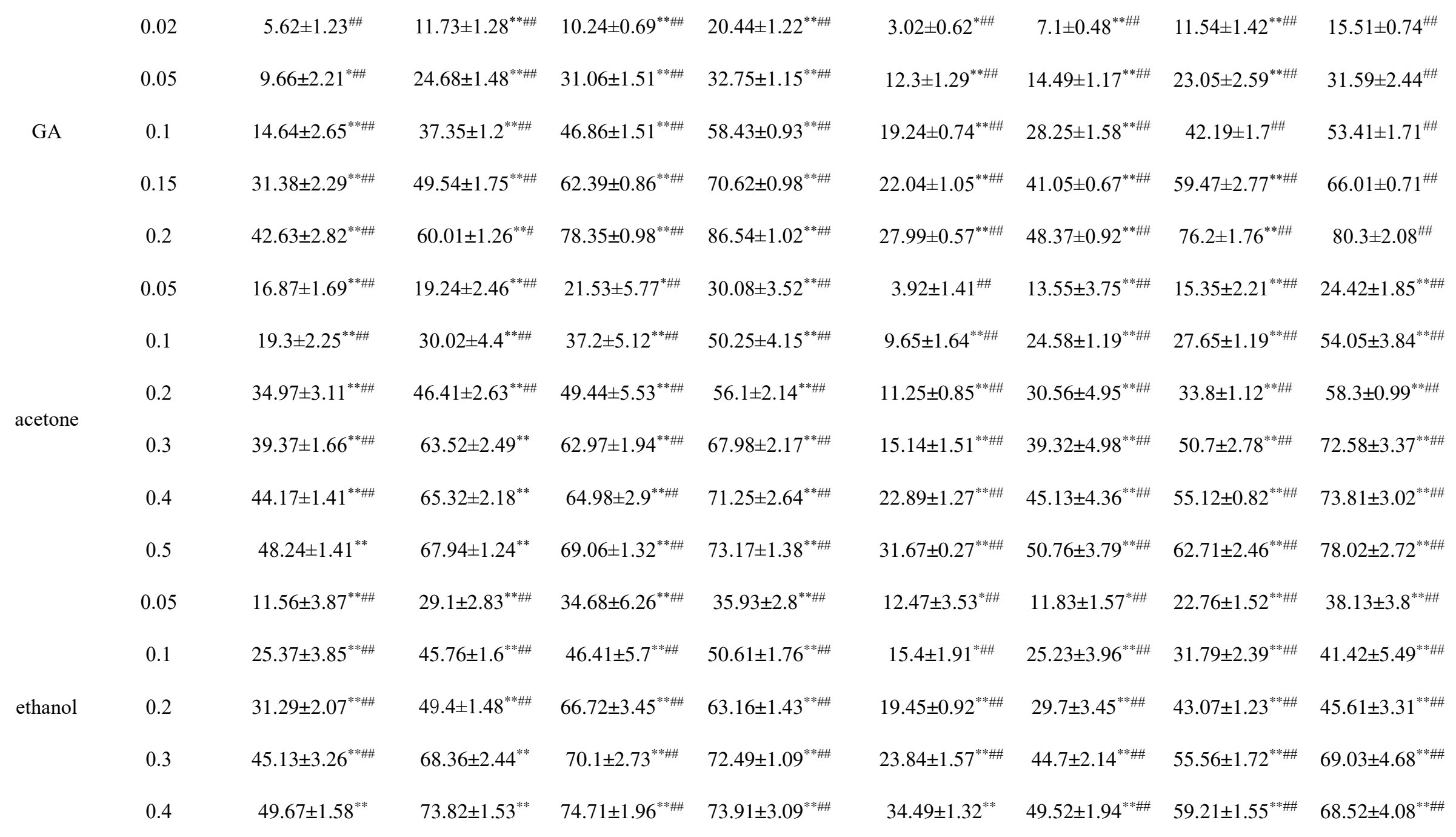




\begin{tabular}{|c|c|c|c|c|c|c|c|c|c|}
\hline & 0.5 & $51.29 \pm 4.0^{* *}$ & $75.44 \pm 2.53^{* *}$ & $76.44 \pm 3.52^{* * \# \#}$ & $76.55 \pm 1.88^{* * \# \#}$ & $38.93 \pm 3.7^{* *}$ & $55.59 \pm 1.68^{* * \# \#}$ & $65.14 \pm 2.17^{* * \# \#}$ & $78.8 \pm 1.14^{* * \# \#}$ \\
\hline \multirow{5}{*}{$\begin{array}{c}\text { methan } \\
\text { ol }\end{array}$} & 0.05 & $8.55 \pm 3.14^{\# \#}$ & $12.17 \pm 2.1^{\text {*\#\# }}$ & $29.8 \pm 2.55^{* * \#}$ & $37.94 \pm 2.48^{* * \# \#}$ & $7.45 \pm 2.56^{* \# \#}$ & $7.84 \pm 1.61^{* \# \#}$ & $12.6 \pm 1.97^{* * \# \#}$ & $15.63 \pm 2.6^{* * \# \#}$ \\
\hline & 0.1 & $11.35 \pm 3.36^{* \# \#}$ & $33.59 \pm 4.16^{* * \# \#}$ & $36.16 \pm 4.04^{* * \# \#}$ & $48.81 \pm 4.14^{* * \# \#}$ & $8.12 \pm 5.35^{* * \#}$ & $23.53 \pm 2.69^{* * \# \#}$ & $28.27 \pm 1.53^{* * \# \#}$ & $31.12 \pm 2.66^{* * \# \#}$ \\
\hline & 0.2 & $23.13 \pm 1.89^{* * \# \#}$ & $48.1 \pm 2.62^{* * \# \#}$ & $52.19 \pm 2.74^{* * \# \#}$ & $60.85 \pm 2.18^{* * \# \#}$ & $16.76 \pm 1.86^{* * \# \#}$ & $31.52 \pm 2.27^{* * \# \#}$ & $38.75 \pm 3.43^{* * \# \#}$ & $50.72 \pm 2.41^{* * \# \#}$ \\
\hline & 0.3 & $31.07 \pm 7.91^{* * \# \#}$ & $60.76 \pm 3.52^{* *}$ & $64.35 \pm 2.45^{* * \# \#}$ & $66.95 \pm 2.06^{* * \# \#}$ & $21.31 \pm 5.76^{* * \#}$ & $38.6 \pm 2.43^{* * \#}$ & $46.91 \pm 1.85^{* * \#}$ & $64.05 \pm 3.67^{* * \#}$ \\
\hline & 0.4 & $36.76 \pm 2.6^{* * \#}$ & $63.79 \pm 3.01^{* *}$ & $65.7 \pm 2.58^{* * \#}$ & $69.57 \pm 2.27^{* * \# \#}$ & $25.17 \pm 1.2^{* * \#}$ & $41.41 \pm 2.61^{* * \# \#}$ & $53.4 \pm 1.62^{* * \# \#}$ & $65.43 \pm 1.44^{* * \#}$ \\
\hline \multirow{7}{*}{ aqueous } & 0.5 & $40.76 \pm 2.6^{* * \# \#}$ & $70.07 \pm 3.4^{* *}$ & $72.63 \pm 1.51^{* * \# \#}$ & $73.31 \pm 1.85^{* * \# \#}$ & $34.41 \pm 3.63^{* *}$ & $48.17 \pm 2.37^{* * \# \#}$ & $60.37 \pm 2.0^{* * \# \#}$ & $72.21 \pm 2.69^{* * \# \#}$ \\
\hline & 0.05 & $3.32 \pm 1.37^{\# \#}$ & $7.55 \pm 0.68^{* \# \#}$ & $15.42 \pm 1.22^{* * \# \#}$ & $22.72 \pm 1.05^{* * \# \#}$ & $1.71 \pm 1.09^{\# \#}$ & $3.85 \pm 0.63^{* \# \#}$ & $6.94 \pm 0.74^{* \# \#}$ & $15.72 \pm 3.4^{* * \# \#}$ \\
\hline & 0.1 & $5.97 \pm 1.78^{* * \#}$ & $16.19 \pm 1.24^{* * \# \#}$ & $34.66 \pm 2.12^{* * \# \#}$ & $36.28 \pm 2.22^{* * \# \#}$ & $4.61 \pm 1.74^{* \# \#}$ & $10.32 \pm 0.97^{* * \#}$ & $15.12 \pm 1.25^{* * \#}$ & $25.16 \pm 4.6^{* * \# \#}$ \\
\hline & 0.2 & $12.58 \pm 0.52^{* * \# \#}$ & $27.05 \pm 1.17^{* * \# \#}$ & $39.08 \pm 0.79^{* * \# \#}$ & $42.94 \pm 0.75^{* * \# \#}$ & $6.38 \pm 0.79^{* \# \#}$ & $16.4 \pm 1.9^{* * \# \#}$ & $28.15 \pm 1.45^{* * \# \#}$ & $31.7 \pm 2.39^{* * \# \#}$ \\
\hline & 0.3 & $22.4 \pm 1.72^{* * \#}$ & $35.72 \pm 2.25^{* * \# \#}$ & $48.27 \pm 0.66^{* * \# \#}$ & $52.97 \pm 0.96^{* * \# \#}$ & $13.48 \pm 1.7^{* * \#}$ & $27.76 \pm 0.69^{* * \# \#}$ & $28.16 \pm 1.45^{* * \#}$ & $45.75 \pm 4.96^{* * \# \#}$ \\
\hline & 0.4 & $23.35 \pm 2.01^{* * \# \#}$ & $42.55 \pm 1.86^{* * \# \#}$ & $50.79 \pm 1.07^{* * \# \#}$ & $53.79 \pm 1.77^{* * \# \#}$ & $25.73 \pm 0.94^{* * \# \#}$ & $45.43 \pm 0.84^{* * \# \#}$ & $59.03 \pm 0.71^{* * \#}$ & $59.92 \pm 2.78^{* * \#}$ \\
\hline & 0.5 & $31.99 \pm 0.83^{* * \# \#}$ & $48.40 \pm 1.8^{* * \# \#}$ & $60.43 \pm 1.89^{* * \# \#}$ & $64.49 \pm 1.89^{* * \#}$ & $31.99 \pm 0.83^{* *}$ & $48.40 \pm 1.8^{* * \#}$ & $60.43 \pm 1.89^{* * \#}$ & $64.49 \pm 1.89^{* * \# \#}$ \\
\hline
\end{tabular}

Note: Mean values were tested for normality before proceeding to the parametric test; one- way ANOVA followed by Tukey pairwise comparisons at $95 \%$ confidence. Value of $P<0.05$ was statistically significant. At the same time, compared with the blank control group, $* P<0.05,{ }^{* *} P<0.01$, compared with the positive control group (5-FU) \# $P<0.05$, \#\# $P<0.01$. 
Table 5 IC 50 values of Caco-2 and HCT-116 cells.

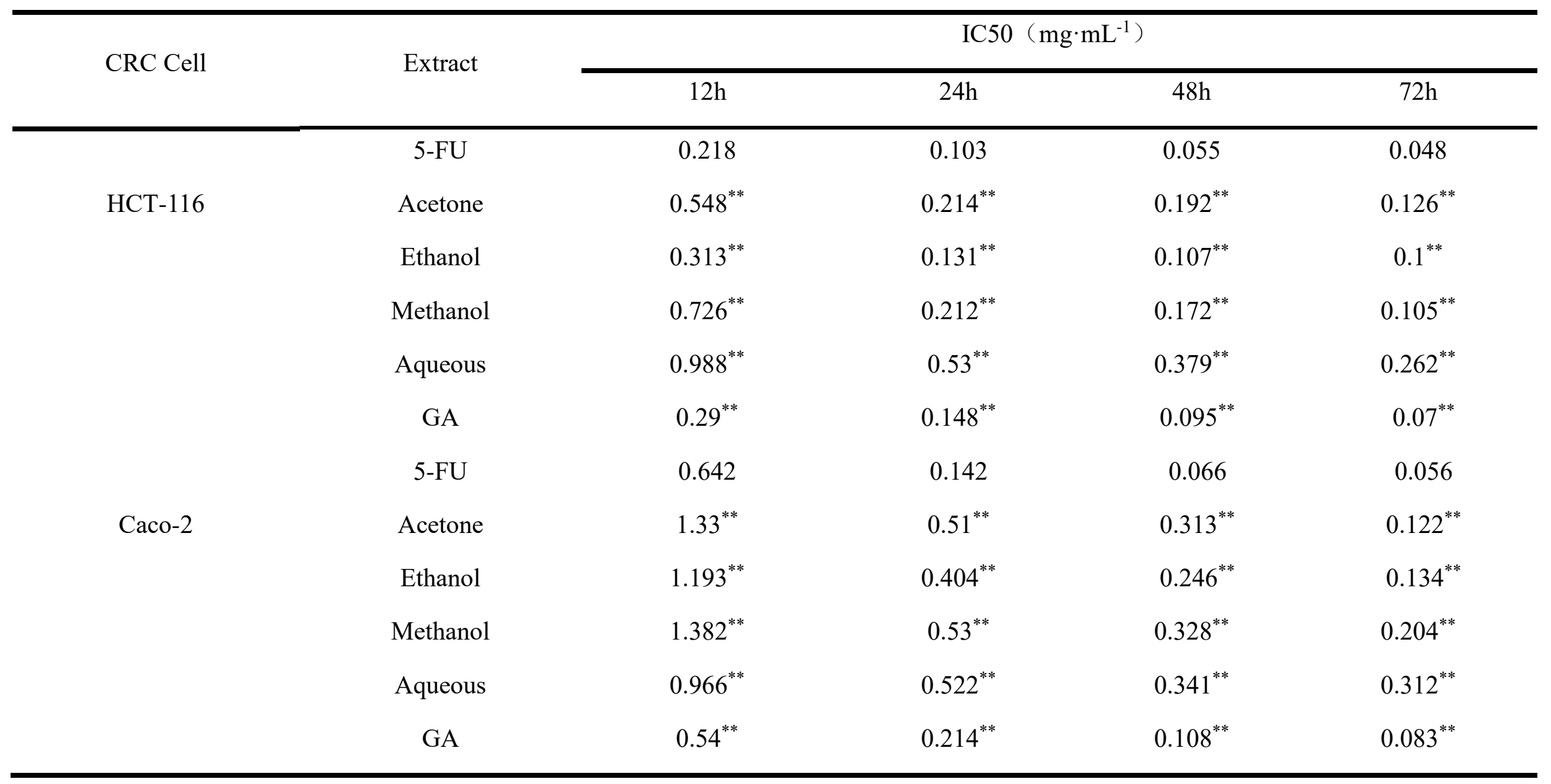

Note:The IC50 value calculated by SPSS 26 . Compared with 5 -fu, $* P<0.05, * * P<0.01$ 


\section{Wound-healing assay}

The wound healing assays indicated that the scratches of the control group were almost cured after $24 \mathrm{~h}$, while the scratches of QIG-treated groups were sustained especially at the concentration of $0.5 \mathrm{mg} \cdot \mathrm{mL}^{-1}$. According to Fig5 (A, B), For the two kinds of CRC cells, the migration distance of ethanol extract was the shortest in extracts. Fig. 6 and Table 6 show the migration of cells after intervention by tested drugs.

Table 6 Effects of tested drugs on migration of two CRC cells

\begin{tabular}{|c|c|c|c|}
\hline Drug & Concentration $\left(\mathrm{mg} \cdot \mathrm{mL}^{-1)}\right.$ & \multicolumn{2}{|c|}{ Migaeration rate(\%) } \\
\hline $5-f u$ & 0.1 & $17.93 \pm 1.95 * *$ & $6.48 \pm 1.69 * *$ \\
\hline \multirow[t]{2}{*}{ GA } & 0.1 & $70.14 \pm 1.45^{* * \# \#}$ & $82.87 \pm 1.76^{* * \# \#}$ \\
\hline & 0.2 & $20.07 \pm 1.7 * * \# \#$ & $43.74 \pm 1.57^{* * \# \#}$ \\
\hline \multirow[t]{2}{*}{ QIG Acetone extract } & 0.1 & $76.27 \pm 3.02 * \#$ & $85.33 \pm 3.32 * * \#$ \\
\hline & 0.3 & $43.88 \pm 5.7 * * \#$ & $73.87 \pm 3.51 * * \#$ \\
\hline
\end{tabular}




\begin{tabular}{|c|c|c|c|}
\hline \multirow[t]{3}{*}{ QIG Ethanol extract } & 0.1 & $53.51 \pm 2.12 * * \#$ & $73.87 \pm 1.96$ **\#\# \\
\hline & 0.3 & $33.02 \pm 1.47 * * \# \#$ & $52.28 \pm 1.99 * * \# \#$ \\
\hline & 0.5 & $23.52 \pm 2.9 * * \# \#$ & $35.15 \pm 1.39 * * \#$ \\
\hline \multirow[t]{3}{*}{ QIG Methanol extract } & 0.1 & $77.08 \pm 2.94 * * \#$ & $789 \pm 2.92 * * \#$ \\
\hline & 0.3 & $34.68 \pm 3.43 * * \#$ & $57.01 \pm 2.87 * * \#$ \\
\hline & 0.5 & $27.6 \pm 2.68 * * \# \#$ & $46.61 \pm 0.99 * * \#$ \\
\hline \multirow[t]{3}{*}{ QIG Aqueous extract } & 0.1 & $74.3 \pm 4.59 * * \#$ & $84.88 \pm 0.59 * * \#$ \\
\hline & 0.3 & $59.8 \pm 2.01 * * \# \#$ & $61.28 \pm 0.81 * * \#$ \\
\hline & 0.5 & $39.06 \pm 3.13^{* * \# \#}$ & $40.14 \pm 1.19 * * \#$ \\
\hline
\end{tabular}

Note: At the same incubation time, compared with the blank control group, ${ }^{*} P<0.05,{ }^{* *} P<0.01$, compared with the positive control group (5-FU) \# $P<0.05$, \#\#P $<0.01$. 

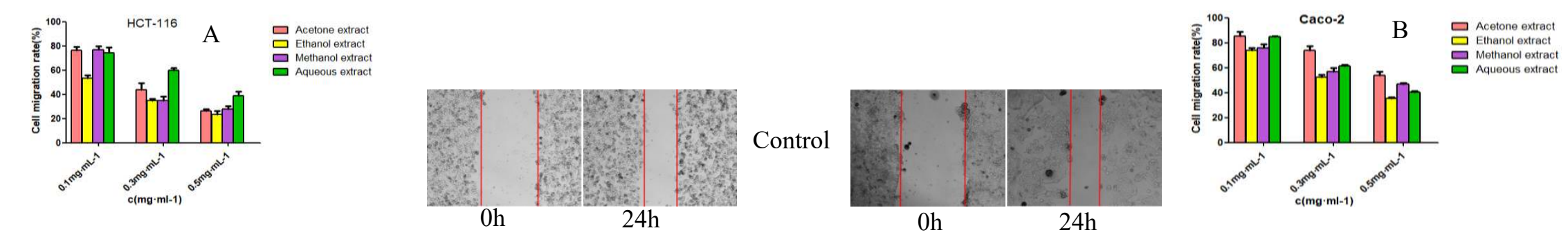

Acetone

Ethanol

Methanol

Aqueous

GA

Acetone

Ethanol

Methanol

Aqueous

GA
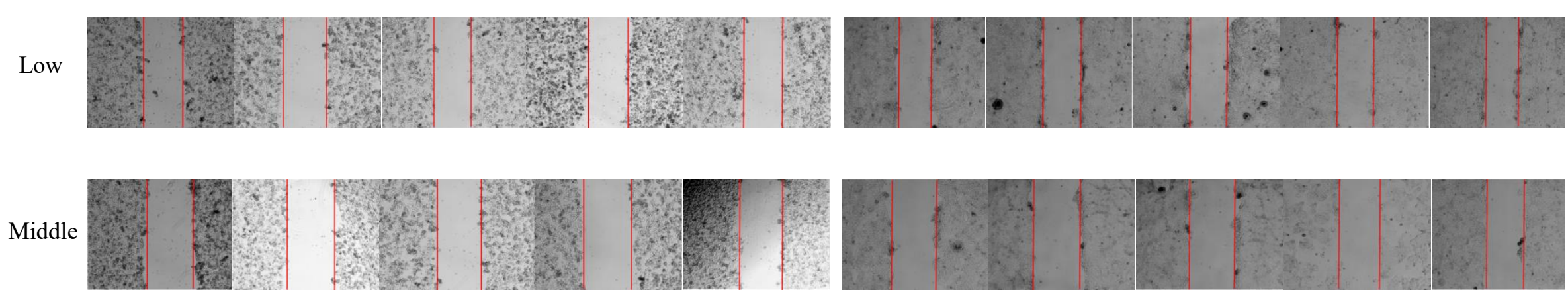

High
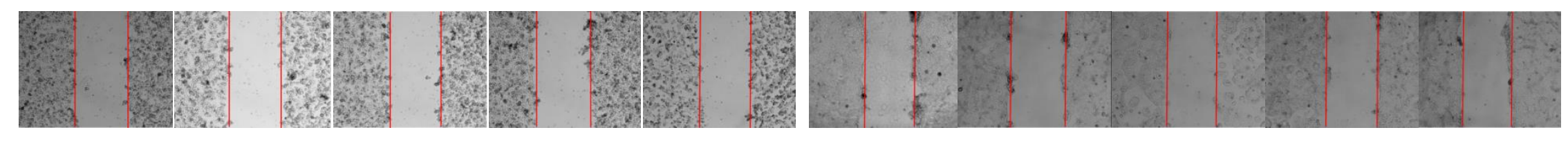

HCT-116

Caco-2 
Fig. 6 QIG could inhibit migration of CRC cells. After administration with low $\left(0.1 \mathrm{mg} \cdot \mathrm{mL}^{-1}\right)$, middle $\left(0.3 \mathrm{mg} \cdot \mathrm{mL}^{-1}\right) \mathrm{and}$ high $\left(0.5 \mathrm{mg} \cdot \mathrm{mL}^{-1}\right) \mathrm{concentration}$ of QIG, and low $\left(0.1 \mathrm{mg} \cdot \mathrm{mL}^{-1}\right)$, middle $\left(0.15 \mathrm{mg} \cdot \mathrm{mL}^{-1}\right)$ and high $\left(0.2 \mathrm{mg} \cdot \mathrm{mL}^{-1}\right)$ concentration of $\mathrm{GA}$, migration of HCT -116 and Caco-2 cells for $24 \mathrm{~h}$ was examined with an inverted microscope $(\times 40)$. A、B: The migration distance of two CRC cells were assessed by GraphPad Prism 5 .

\section{Apoptosis assay}

In order to define whether QIG suppresses cell viability by inducing apoptosis, HCT-116 cells and Caco-2 cells were administrated with QIG extracts for $24 \mathrm{~h}$ and dyed with Annexin V/PI. The apoptotic effect of QIG extracts was assessed by flow cytometry. Comparing with the control group, the apoptosis ratio of HCT-116 and Caco-2 cells treated with QIG extracts $\left(0.3 \mathrm{mg} \cdot \mathrm{mL}^{-1}\right)$ significantly improved in different degrees (Fig. 7). Among them, the apoptosis rate of ethanol extract was the highest after intervention, which was $27 \%$ and $24.9 \%$ for HCT- 116 and Caco- 2 cells respectively, and the rest was methanol $>$ acetone $>$ aqueous. Additionally, Fig. 8 show that with the increase of GA dosage, the number of apoptotic cells increased significantly. The apoptotic HCT-116 cells in low, medium and high dose GA groups increased from $14.0 \%$ in the control group to $16.4 \%, 23.3 \%$ and $30.4 \%$, respectively, and the apoptotic Caco-2 cells increased from 10.5\% in the control group to $17.7 \%$, $21.3 \%$ and $29.3 \%$ respectively. The results showed that GA had obvious apoptosis inducing effect on HCT-116 and Caco-2 cells, and the apoptosis inducing effect in high dose GA group was more obvious.

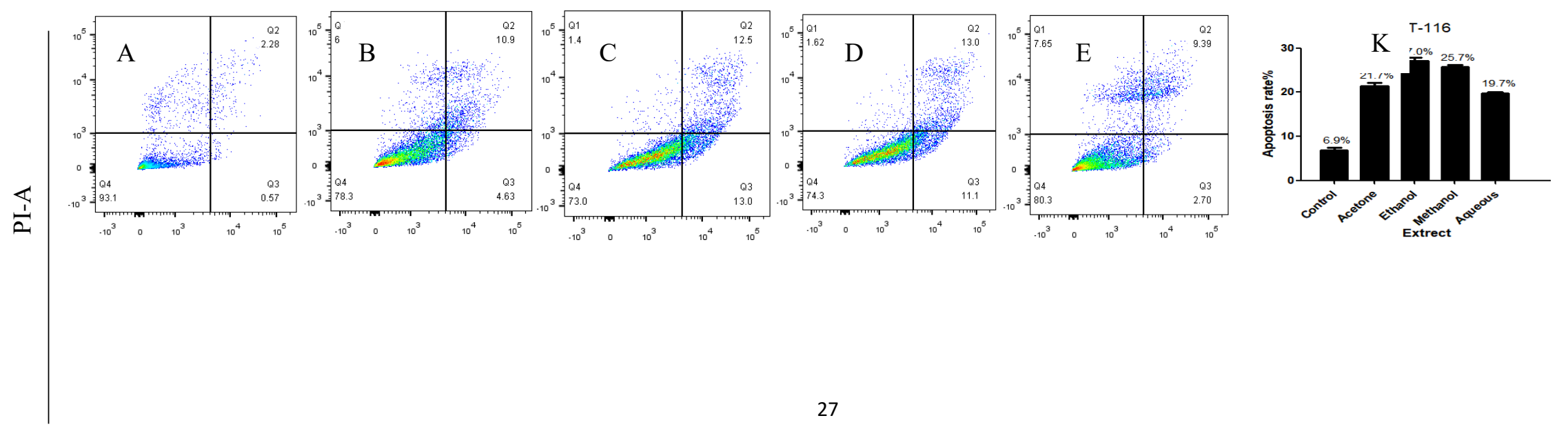



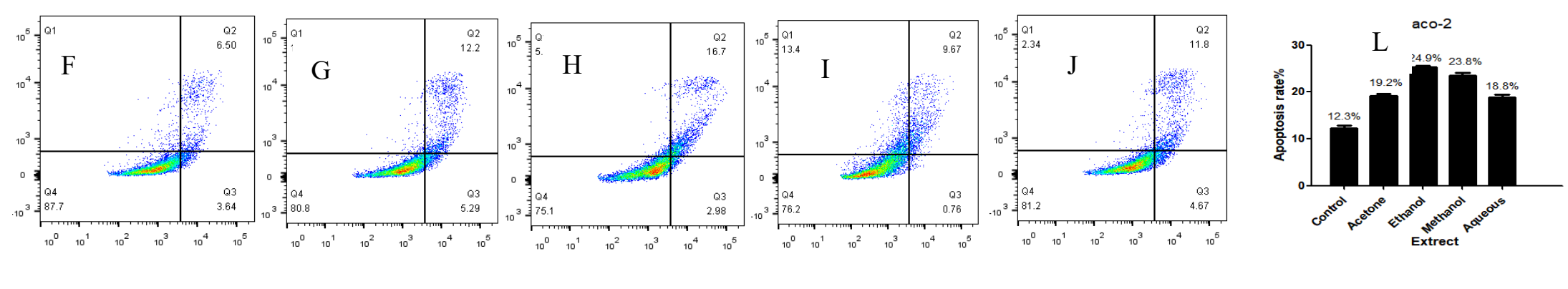

Annexin V-FITC

Fig.7 Apoptosis of two CRC cells treated by each extract. A $\sim$ E was the apoptosis of HCT-116 cells in blank control group, acetone, ethanol, methanol and aqueous extract groups after incubated 24 hours; $\mathbf{F} \sim \mathbf{J}$ was the apoptosis of Caco-2 cells in blank control group, acetone, ethanol, methanol and water extract groups after incubated 24 hours; the concentration of each extract was $0.3 \mathrm{mg} \cdot \mathrm{mL}^{-1} . \mathbf{K} 、 \mathbf{L}$ : The apoptosis rate of HCT-116 and Caco-2 cells incubated with different extracts for 24 hours.
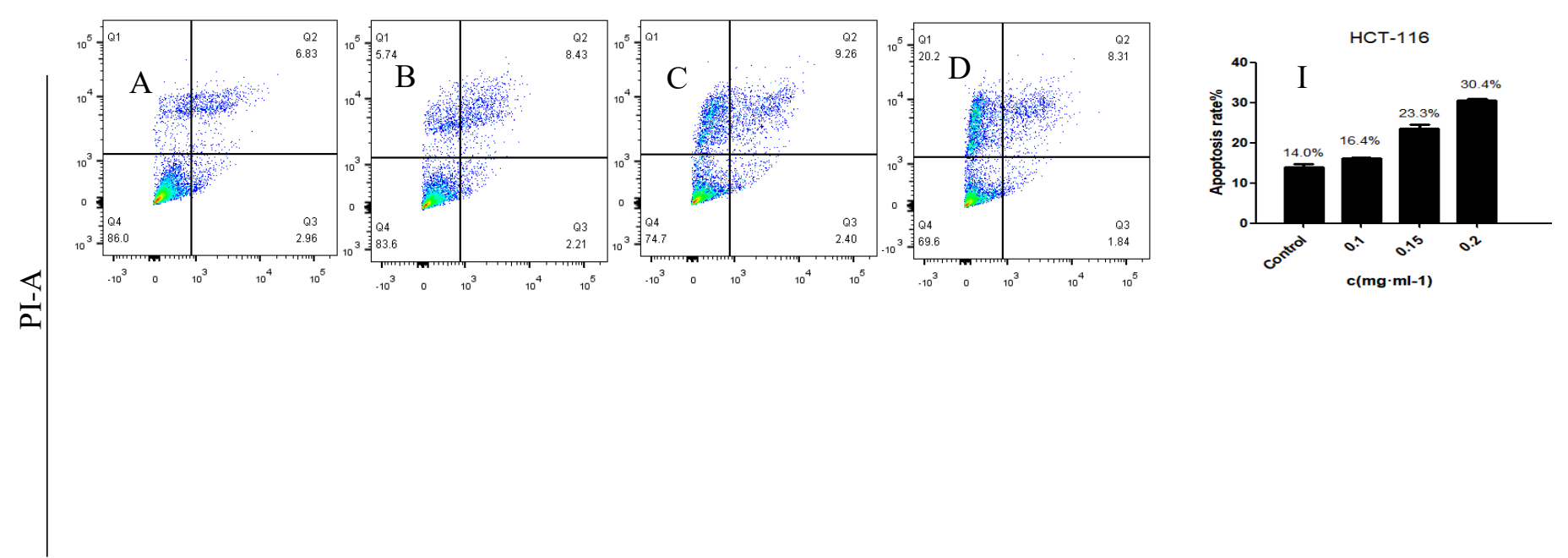

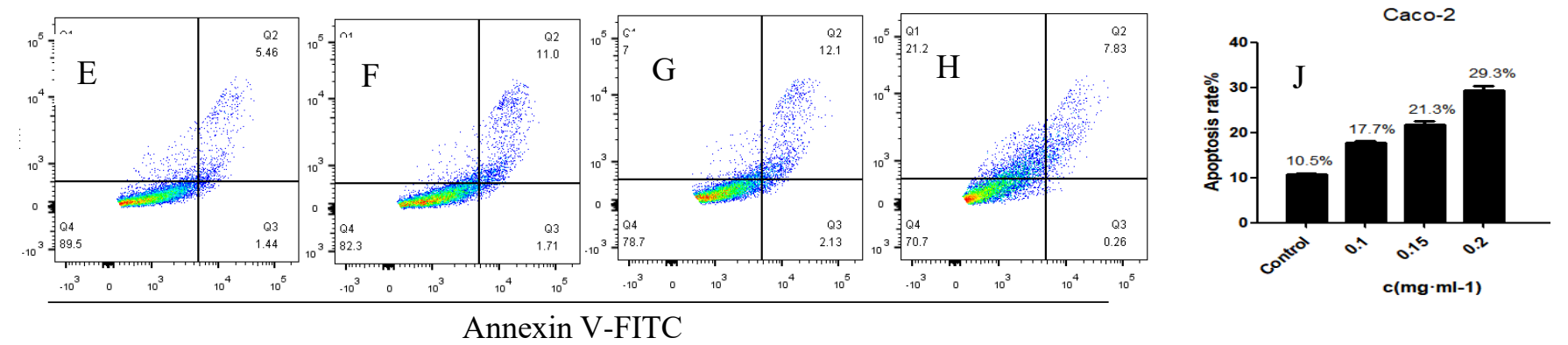

Fig. 8 Apoptosis of two CRC cells treated by GA. A D was the apoptosis of HCT-116 cells in blank control group, GA $\left(0.1 、 0.15 、 0.2 \mathrm{mg} \cdot \mathrm{mL}^{-1}\right)$ after incubated 24 hours; $\mathbf{E} \sim \mathbf{H}$ was the apoptosis of Caco-2 cells in blank control group, GA $\left(0.1 、 0.15 、 0.2 \mathrm{mg} \cdot \mathrm{mL}^{-1}\right)$ after incubated 24 hours; the concentration of each extract was $0.3 \mathrm{mg} \cdot \mathrm{mL}^{-1}$. I J:The apoptosis rate of HCT-116 and Caco-2 cells incubated with different extracts for 24 hours.

\section{Entropy weight}

The entropy weight method was used to determine the objective weight of the index. According to the above CCK-8 assay, wound healing assay and apoptosis assay, a series of index data were obtained, and then the entropy weight method was used as the weighting method of best anti-CRC QIG extract evaluation. Based on Eqs. (2-6), the results of the entropy weight method are given in Table 7, and the final comprehensive score was calculated in Table 8. The result show that, for HCT-116 cells, the comprehensive score order was ethanol $>$ methanol $>$ aqueous $>$ acetone; for Caco-2 cells was ethanol $>$ methanol $>$ acetone $>$ aqueous. The score of ethanol extract was the highest (0.5546 and 0.5436). Therefore, this study proves that the ethanol extract has the strongest inhibitory effect on CRC cells.

Table 7 Objective weights based on entropy model 


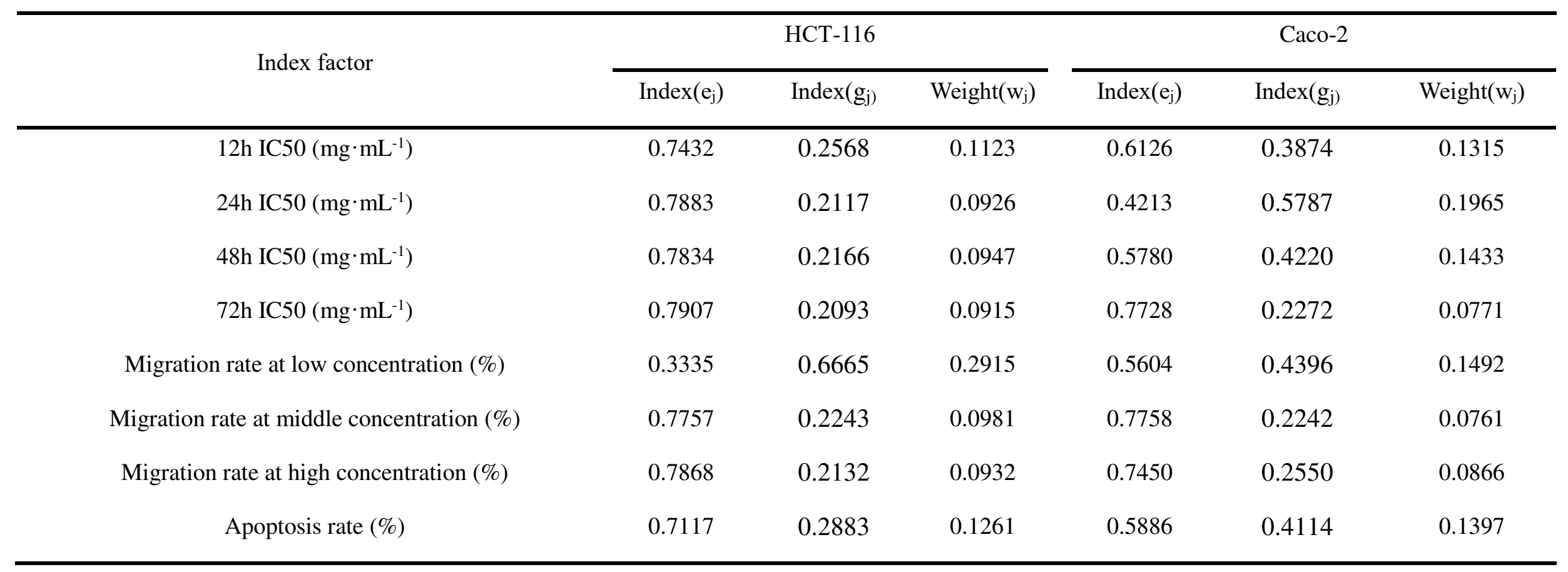

Table 8 The final entropy score of each extract

\begin{tabular}{|c|c|c|c|c|}
\hline Cell & \multicolumn{4}{|c|}{ Entropy score } \\
\hline Caco-2 & 0.1011 & 0.5546 & 0.1989 & 0.1454 \\
\hline
\end{tabular}




\section{Discussion}

With the application and development of omics technology, some scholars divided CRC into goblet cell type, intestinal epithelial cell type, stem cell type, inflammatory type and transforming type according to its pathological characteristics and characteristic expression profile ${ }^{[24]}$. At the same time, scientists found that the patients with inflammatory type of cancer are relatively sensitive to radiotherapy, and can achieve the purpose of preventing the occurrence of cancer through oral aspirin and other anti-inflammatory treatment ${ }^{[25]}$. IBD is a high risk factor for CRC, and the risk of CRC in patients with chronic IBD is significantly higher than that in the general population ${ }^{[26]}$. Meanwhile, some literatures have confirmed that the impact on CRC is not limited to IBD, and the occurrence and development of CRC is related to some occult inflammation ${ }^{\text {[27] }}$. The research of inflammatory bowel disease-related colorectal cancer has important value for the occurrence and development of inflammatory cancer transformation and inflammation related colorectal cancer ${ }^{[28]}$. Nowadays natural products as well as their combination therapy represent a promising approach in the therapy of cancer. Polyphenols are abundant in nature. Because their structures contain phenolic hydroxyl groups, they show a wide range of biological activities, such as anti-inflammatory anti-oxidant, anti-cardio cerebrovascular disease, anti-cancer and anti-virus ${ }^{[29]}$. Free radical reaction is closely related to the occurrence and development of cancer. In the complex process of carcinogenesis, peroxides may play an important role. Antioxidants can scavenge free radicals, interrupt or terminate the oxidation reaction of free radicals ${ }^{[30]}$. In addition, polyphenols are easily oxidized to quinones and easily capture free radicals such as reactive oxygen. Therefore, polyphenols have strong ability to scavenge free radicals and antioxidants can inhibit the occurrence of cancer metastasis by removing active oxides. The occurrence of cancer is the result of multiple factors, and polyphenols can play an anti-cancer role through multiple mechanisms. Such as silybin gallic acid inhibiting angiogenesis ${ }^{[31]}, 5$-arylthiothiazolidone inhibiting tyramide DNA phosphodiesterase $\mathrm{I}^{[32]}$, and catechin inhibiting met kinase in human CRC cells ${ }^{[33]}$. Additionally, Antioxidant represses the cancer metastasis through scavenging ROS ${ }^{[34]}$, Hence, scavenging abnormally produced ROS can be considered to be one of the alternative methods for treating inflammatory diseases. However, high doses of natural antioxidants such as polyphenol can induce side effects on health. Further, synthetic antioxidants are still controversial in regards to their safety and their complicated synthesis ${ }^{[35]}$. In that perspective, we focus on polyphenol rich natural product QIG's application as anti inflammatory, anti oxidant and anti-carcinogen agent. The present study aims to screen the anti CRC potential of QIG extracts without compromising its 
toxicological aspects. At the same time, find out the potential relationship between material basis of QIGs extract and its pharmacodynamic basis.

In this study, different polar solvent were used for extracting QIG powder in order to investigate its antioxidant effects difference of compounds. The polar solvents with high polarity index, aqueous $\left(\mathrm{P}^{\prime}=9\right)$, followed by ethanol $\left(\mathrm{P}^{\prime}=5.2\right)$, methanol $\left(\mathrm{P}^{\prime}=5.1\right)$ and acetone $\left(\mathrm{P}^{\prime}=\right.$ 5.1) were used due to their ability to extract a broad spectrum of bioactive compounds present in the plant. This was confirmed by Muñoz ${ }^{[36]}$ in the search for antimalarial compounds from Bolivian plants using several polar solvents. 5-FU is the earliest and most widely used anti metabolic chemotherapy drug in clinic. Compared with other chemotherapy drugs, 5-FU has good curative effect on gastrointestinal cancer and other solid cancer ${ }^{[37]}$, and acts as a positive control drug in most cancer drug research. Cell proliferation, apoptosis, cell migration, autophagy and cell death are the most commonly used pharmacodynamic evaluation indexes at cell experiment. HCT-116 and Caco-2 are the main common CRC cells. In this research, the proliferation, migration and apoptosis of HCT-116 and Caco-2 cells were detected by CCK-8, wound healing assay and flow cytometry. According to the above process, a series of index data were obtained, and then the entropy weight method was used as the weighting method of best anti-CRC extract evaluation. Meanwhile, it is the first time that entropy weight method is used to analyze the results of in vitro experiments

There are many compounds in QIG. We chose the more representative polyphenols, tannins and GA for analysis through literature review ${ }^{[38]}$. The result of analytical methods indicated that the contents of polyphenols, tannins and GA in extracts from high to low were aqueous $>$ methanol $>$ ethanol $>$ acetone, which were the highest in the aqueous extract, reaching $562.66 \pm 8.45 \mathrm{mg} \cdot \mathrm{mL}^{-1}, 463.85 \pm 4.62 \mathrm{mg} \cdot \mathrm{mL}^{-1}, 169.86 \pm$ $3.24 \mathrm{mg} \cdot \mathrm{mL}^{-1}$, respectively, and the content order of them in residues is opposite to that in extracts. Through the study of material basis, the effective components in the residues were far lower than those in the extracts (which was only 1/10-1/5 of the extract), so just the extracts were tested in pharmacodynamics experiment. In vitro pharmacodynamics experiment exhibited all four extractsthat could inhibit the proliferation and migration, induce apoptosis of CRC cells in different degrees, and this is in agreement with the study by Zhang $\mathrm{H}^{[16]}$ in which aqueous extracts of QIG exhibited a promising anti CRC activity in vitro against the HT-29 and CT-26 strain of CRC. The entropy score of ethanol extract ranks first (0.5546 and 0.5436), followed by methanol (0.2264 and 0.1989), acetone (0.1961 and 0.1011) and aqueous (0.0596 and 0.1454$)$. After the intervention of ethanol extract, the proliferation inhibiting rate of ethanol extract on HCT-116 and Caco-2 cells reached 76.55\% and 78.8\%, 
migration inhibition rate reached $76.48 \%$ and $64.85 \%$, and the induced apoptosis rate increased by $20.1 \%$ and $12.6 \%$. Therefore, the comprehensive assessment showed that the ethanol extract promising good selectivity compared to the other extracts, and is preferable for further mechanism research. These findings will lead to further studies on the bioactivity-guided isolation of compounds from the ethanol extracts of QIG, and the specific pathway of its in vitro efficacy should be clarify to lay a foundation for in vivo research.

The presence of phenolic compounds in QIG has been extensively quantified, with $50 \%-70 \%$ polyphenols as principal compounds ${ }^{[39]}$. This kind of water-soluble components is obviously the most in the aqueous extract, but in this anti CRC activity test, the ethanol extract of QIG shows the strongest effect. In another antimalaria test, the acetone and methanol extract of QIG have the strongest effect ${ }^{[40]}$. These results indicated that the efficacy of QIG does not completely depend on the content of polyphenols or tannins. This result may be caused by the different proportion of components, and maybe the combination of polyphenols with other water-soluble substances has some synergistic orantagonistic characteristics. This needs to be further explained from the mechanism of action of traditional medicine and the pathogenesis of the disease, and it may also need to find the answer from nearly $30 \%$ of the components of QIG, which have not been found yet.

\section{Conclusions}

In summary, the compounds of different extracts of four kind of different polar solvent extracts of QIG were analyzed and the anti CRC activity was detected In this study (Fig.9). Compound analysis result shows that aqueous extract contain the most active compounds. However, In pharmacodynamic experiments, the ethanol extract but not the aqueous promising the strongest anti CRC activity. Therefore, for the effective application of QIG in CRC prevention and treatment, the main bioactive ingredients in QIG ethanol extract should be investigated in the following study. This research also suggests that the anti CRC effect of QIG is not directly related to the content of polyphenols compounds. This research provides experimental basis for further mechanism research and the application of QIG in Inflammation associated CRC therapy as a complement and alternative medicine. 


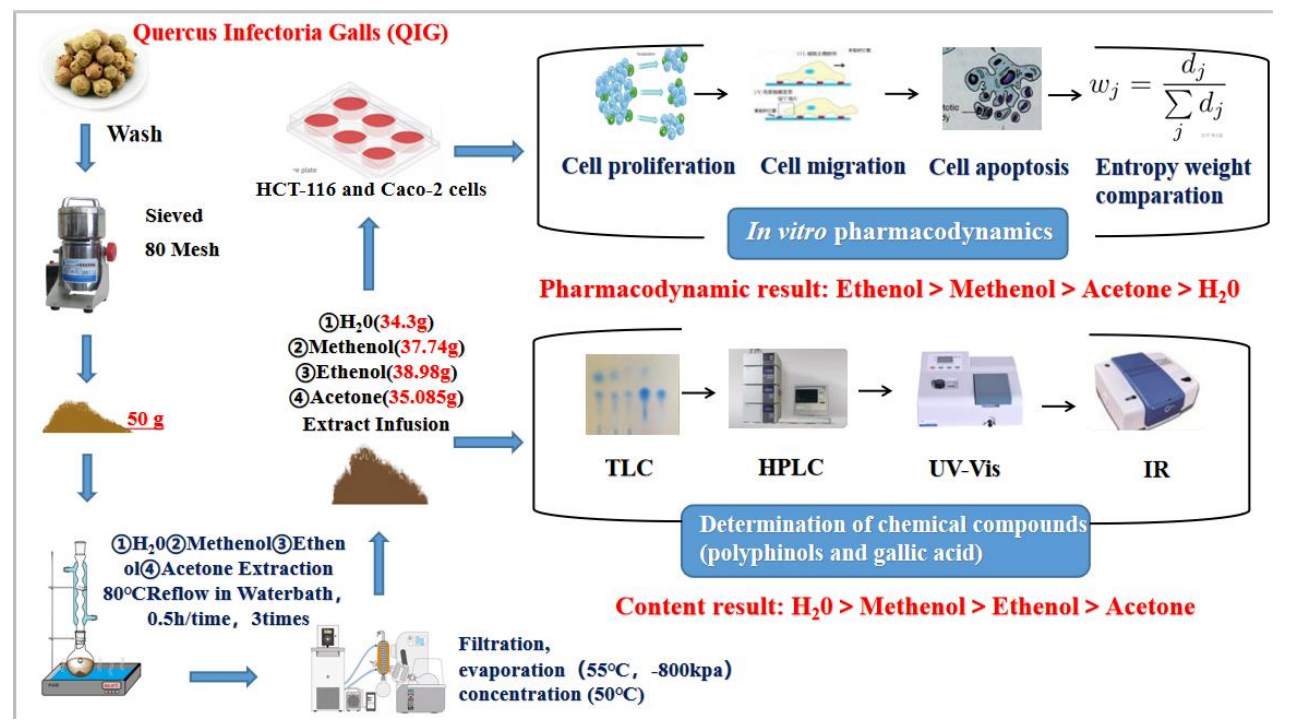

Fig. 9 Overview of compounds analysis and anti colorectal cancer efficacy of different polar solvent extracts of QIG

\section{Abbreviations}

CRC:Colorectal cancer; TM:Traditional Medicine; QIG:Quercus infectoria galls; GA: gallic acid; IBD:inflammatory bowel disease;TLC: Thin Layer Chromatography; UV-Vis: Ultraviolet-visible spectrophotometry; HPLC: High Performance Liquid Chromatography; IR: Infrared spectroscopy

\section{Acknowledgments}


I would like to show my deepest gratitude to my kind ralitives, who has continued and steadfast supported my study; to my tutor, Dr.Mubarak Iminjan , a respectable, responsible and resourceful scholar, who has provided me with valuable guidance in every stage of the writing of this manuscript.

\section{Author contributions}

Aliya Elham performed the experiment and data analysis. Abdulaziz Arkin contributed significantly to analysis and manuscript preparation. Gulina Kalimanjan helped perform the analysis with constructive discussions. Arfidin Anwar participated in the design of this study. Wenjie Luo assist in microscopic identification of plant. Mubarak Iminjan, Corresponding author, contributed to the conception of the study and manuscript edition.

\section{Funding}

This work was supported by Natural Science Foundation of Xinjiang Uygur Autonomous Region (2021D01C259)

\section{Availability of data and materials}

The datasets for supporting the outcomes of the study are included in the article and additional information can be provided on request made to the corresponding author.

\section{Ethics approval and consent to participate}

The purchase of plant material complyed with the IUCN Policy Statement on Research Involving Species at Risk of Extinction and the Convention on the Trade in Endangered Species of Wild Fauna and Flora. 


\section{Consent for publication}

Not applicable

\section{Competing interests}

The authors declare no conflict of interest.

\section{References}

[1] Eslami M,Yousefi B,Kokhael P,et al. Importance of probiotics in the prevention and treatment of colorectal cancer. J Cell Physiol, 2019, 234(10): 17127-17143. http://10.1002/jcp.28473

[2] Bray F, Ferlay J, Soerjomataram I, et al. Global cancer statistics 2020: GLOBOCAN estimates of incidence and mortality worldwide for 36 cancers in 185 countries. CA Cancer J. Clin. 2021;71:209-249. http://10.3322/caac.21492

[3] Piawah S, Venook AP. 2019. Targeted therapy for colorectal cancer metastases: a review of current methods of molecularly targeted therapy and the use of tumor biomarkers in the treatment of metastatic colorectal cancer. Cancer.125,4139-47. http://10.1002/cncr.32163

[4] Libby P, Kobold S. Inflammation: a common contributor to cancer,aging,and cardiovascular diseases-expanding the concept of cardiooncology. Cardiovasc Res, 2019, 115(5): 824-829. http://10.1093/cvr/cvz058

[5] Padoan A, Plebani M, Basso D. Inflammation and pancreatic cancer:focus on metabolism,cytokines,and immunity. Int J Mol Sci, $2019,20(3)$ : 676. http://10.3390/ijms20030676

[6] Luo H, Vong CT, CHEN H, et al. Naturally occurring anti-cancer compounds:shining from Chinese herbal medicine.Chin Med, 2019 , 14: 48. http://10.1186/s13020-019-0270-9 
[7] Hussein AO, Mohammed GJ, Hadi MY, et al. Phytochemical screening of methanolic dried galls extract of Quercus infectoria using gas chromatography-mass spectrometry (GC-MS) and fourier transform-infrared (FT-IR). J Pharmacogn Phytoth, 2016, 8 (3) :49-59. http://10.5897/JPP2015.0368

[ 8 ] Nimri LF, Meqdam M, Alkofahi A. Antibacterial activity of Jordanian medicinal plants. Pharm Biol. 1999, 37 (3) :196-201. http://info:doi/10.1076/phbi.37.3.196.6308

[9] Drug standards of the Ministry of health of the people's Republic of China, Uygur medicine volume. 1999

[10] Song Y.P. 2021. Effect of Xipayi gingival consolidation solution on periodontal index and cytokines in gingival crevicular fluid of patients with chronic periodontitis. Chin. Med. Abstract (otolaryngology). 36(10),105-107. http://10.19617/j.issn1001-1307.2021.02.105

[11] Amin MN, Hussain MS, Sarwar MS,et al.How the association between obesity and inflammation may lead to insulin resistance and cancer.Diabetes Metab Syndr,2019,13(2):1213-1224. https://10.1016/j.dsx.2019.01.041

[12] Schwiebs A, Herrero San Juan M, Schmidt KG, et al.Cancerinduced inflammation and inflammation-induced cancer in colon:a role for S1P lyase.Oncogene,2019,38(24):4788-4803. http://10.1038/s41388-019-0758-x

[13] Kostic AD, Chun E, Meyerson M, et al. Microbes and inflammation in colorectal cancer. Cancer Immunol Res, 2013,1(3):150-157. https://10.1016/j.smim.2017.09.006

[14] Wang D, Dubois RN. The role of COX-2 in intestinal inflammation and colorectal cancer.Oncogene,2010,29(6):781-788. http://10.1038/onc.2009.421

[15] Imit M. Study on the mechanism of anti ulcerative colitis by gallic extract based on il-6/jak-stat3 signaling pathway(Master Dessertation). Southwest Medical University, 2018

[16] Zhang H, Wang Y, Liu J, et al. Traditional Uyghur medicine Quercus infectoria galls water extract triggers apoptosis and autophagic cell death in colorectal cancer cells. BMC Complementary Med. Therapies 2020, 371 https://doi.org/10.1186/s12906-020-03167-0

[17] Lu MQ. Studies on physicochemical properties and biological activities of ultramicropowder of galls of Quercus infectoria (Master Dessertation). 2019.Xinjiang Medical University, Urumqi.

[18] Shrestha S, Kaushik VS, Eshwarappa RSB, et al. Pharmacognostic studies of insect gall of Quercus infectoria Olivier (Fagaceae). Asian Pac. J. Trop. 
Biomed. 4,35-39. https://doi.org/10.1016/S2221-1691(14)60205-7

[19] Baharuddin NS, Abdullah H, Wan Abdul Wahab WNA, 2015. Anti-Candida activity of Quercus infectoria gall extracts against Candida species. J Pharm Bioallied Sci. 2014;7,15-20. https://doi. org/10.4103/0975-7406.148742

[20] Mad MN, Roslan K, Sazeli AW,et al. In vitro antimalarial and toxicological activities of Quercus infectoria (Olivier) gall extracts. Malays J Med Sci. 2020;27(4):36 - 50. https://doi.org/10.21315/mjms2020.27.4.4

[21] ICH, Q2 (R1) validation of analytical procedures. In Proceedings of International Conference on Harmonization, Geneva, 2005.

[22]Jenifer MA, Jha MK. Comparison of Analytic Hierarchy Process, Catastrophe and Entropy techniques for evaluating groundwater prospect of hard-rock aquifer systems. J Hydrology, 2017, 548:605-624. https://doi.org/10.1016/j.jhydrol.2017.03.023

[23] Long F. Isolation and identification of chemical constituents of gall (Master Dessertation). 2017. Shihezi University, Shihezi.

[24] Itzkowitz SH,Yio X.Inflammation and cancer IV. Colorectal cancer in inflammatory bowel disease:the role of inflammation. Am J Physiol Gastrointest Liver Physiol, 2004, 287(1): G7-17. http://10.1007/s11888-009-0006-9

[25] Bergman M, Djaldetti M, Salman H, et al.Inflammation and colorectal cancer:does aspirin affect the interaction between cancer and immune cells? Inflammation, 2011, 34(1): 22-28. http://10.1007/s10753-010-9203-6

[26] Dirnhofer S, Zippelius A. Cancer immunology, inflammation, and tolerance:an introduction.Virchows Arch, 2019, 474(4): 405-406. http://10.1007/s00428-019-02547-3

[27] Lin HL, Lin HC, Lin CC, et al. Increased risk of colorectal cancer among patients with biliary tract inflammation:a 5-year follow-up study. Int J Cancer, 2011, 128(2):447-452. http://10.1002/ijc.25354

[28] Kraus S,Arber N.Inflammation and colorectal cancer.Curr Opin Pharmacol,2009,9(4):405-410. https://10.1007/s00281-012-0352-6

[29] Liu XH, Wei FJ, Wang XS, et al. Research progress on bioactivity of polyphenols. Chinese Journal of pharmaceutical industry, 2021,52 (04): $471-483$. http://10.16522/j.cnki.cjph.2021.04.005

[30] Tao XF, vay Liang w (bill) go, Xiao GS, Research progress of reactive oxygen species mediated tumor microenvironment in the occurrence and development of pancreatic cancer. Acta physiologica Sinica: 1-22 [2021-0410] https://doi.org/10.13294/j.aps.2021.0011. 
[31] Cryan LM,Bazinet L, Habeshian KA,et al.1,2,3,4,6-Penta-O-galloyl- $\beta$-D-glucopyranose inhibits angiogenesis via inhibition of capillary morphogenesis gene 2.J Med Chem,2013,56(5):1940-1945. http://10.1021/jm301558t

[32] Sirivolu VR, Vernekar S, Marchand C, et al. 5-Arylidenethioxothiazolidinones as inhibitors of tyrosyl-DNA phosphodiesterase I. J Med Chem, 2012, 55(20):8671-84. http://10.1021/jm3008773

[33] Lei S, Ding Y, Fu Y, et al. The preclinical analysis of TW-37 as a potential anti-colorectal cancer cell agent. PloS One, 2017, 12(10):e0184501. http://doi:10.1371/journal.pone.0184501

[34] Yang J.Y., Wu H.Z., Hu Y., et al. Natural antioxidants: a new approach to cancer metastasis [J]. Chinese Journal of clinical pharmacology and therapeutics, 2007(04): 366-370. http://10.1039/d0sc03246h

[35] Ndhlala A R , Moyo M , Staden J V . Natural antioxidants: fascinating or mythical biomolecules?[J]. Molecules, 2010, 15(10):6905-30. https://doi:10.3390/molecules 15106905

[36] Muñoz V, Sauvain M, Bourdy G, et al.The search for natural bioactive compounds through a multidisciplinary approach in Bolivia. Part II. Antimalarial activity of some plants used by Mosetene indians. J Ethnopharmacol. 2000, 69( 2):139-155..

https://doi.org/10.1016/S0378-8741(99)00096-3

[37] Fu GY, New Cancer Drug Handbook.Beijing Jindun publishing house, 2016.04.35.

[38] Elham A, Arken M, Kalimanjan G, et al. A review of the phytochemical, pharmacological, pharmacokinetic, and toxicological evaluation of Quercus Infectoria galls. 2021.J Ethnopharm, 273, 113592. https://doi.org/10.1016/j.jep.2020.113592

[39] Abdullah, AR, Hapidin H, Abdullah H. The role of semipurified fractions isolated from Quercus infectoria on bone metabolism by using hFOB 1.19 human fetal osteoblast cell model. Evidence-based Complement Altern Med. 2018.5319528. https://doi.org/10 .1155/2018/5319528

[40] Zin N, Mohamad MN, Roslan K, et al. In Vitro Antimalarial and Toxicological Activities of Quercus infectoria (Olivier) Gall Extracts[J]. Malays J Med Sci, 2020, 27(4):36-50. https://doi.org/10.21315/mjms2020.27.4.4 